\title{
ADJUSTMENT OF THE BED SURFACE SIZE DISTRIBUTION OF GRAVEL-BED RIVERS IN RESPONSE TO CYCLED HYDROGRAPHS
}

\author{
Gary Parker \\ Department of Civil and Environmental Engineering and Department of Geology, \\ University of Illinois, Urbana, Illinois, 61801, USA, parkerg@uiuc.edu \\ Marwan Hassan \\ Department of Geography, University of British Columbia, Vancouver, British \\ Columbia, V6T 1Z2, Canada, mhassan@geog.ubc.ca \\ Peter Wilcock \\ Department of Geography and Environmental Engineering, Johns Hopkins University, \\ Baltimore, Maryland, 21218, USA, wilcock@jhu.edu
}

\begin{abstract}
Mountain gravel-bed rivers typically display a surface layer that is armored. That is, the surface layer visible at low flow is coarser than both the substrate and mean annual bedload transported. The surface layer is difficult to sample at the high flows that transport most of the gravel. As a result, the question as to whether the surface layer remains armored at high flows is something of a mystery. The few measurements available suggest that some form of armoring may be in place at high flows as well. In lieu of more measurements, numerical modelling provides an avenue to explore this issue. Research results are presented using a 1D model of aggradation and degradation to mobile-bed equilibrium in gravel-bed streams. In the model, a hydrograph is cycled repeatedly so that water discharge goes up and down in time. The magnitude of the bedload feed rate and the size distribution of the feed material are, however, held constant at the upstream end of the reach. As a result, the final mobile-bed equilibrium attained is characterized by a bed at the upstream end of the reach that cyclically degrades and coarsens at high flow (when the sediment feed rate is not sufficient) and aggrades and becomes finer at low flow (when there is an excess of sediment feed). Only a short distance downstream, however, a remarkable tradeoff occurs. The bed adjusts so that over the great majority of the modelled reach the bed elevation and surface size distribution become invariant in time, hardly changing at all from low flow to high flow. The bedload transport rate and size distribution, however, fluctuate strongly with the hydrograph. That is, the higher flows support a higher transport rate of coarser material and the lower flows support a lower transport rate of finer material. The implication is that rivers subject to repeated hydrographs can evolve so that neither surface grain size distribution nor mean bed elevation (averaged over bars) need change much with flow, nearly all the variation being absorbed by the bedload. If this is true, it provides a most useful result; the surface grain size distribution seen at low flow may be very close to that seen at high flow. The results have been verified with two transport relations, that of Parker and that of Wilcock and Crowe. The reasons behind this simple result are explored in terms of a "hydrograph boundary layer," downstream of which the effect of the hydrograph on bed elevation and surface size distribution become negligible. The
\end{abstract}


results of the numerical model also indicate that for a given hydrograph, the degree to which the surface is armored relative to the grain size distribution of the feed sediment decreases with increasing gravel feed rate.

Keywords: gravel rivers, armor, hydrograph, bedload

\section{INTRODUCTION}

The topic of this paper can be introduced in terms of a metaphor. The metaphor is based on a three-panel cartoon from the "Far Side" series of Gary Larson (1984). In the top panel, four cows are standing on their two hind legs, looking perfectly at ease, when one of them shouts "car!". Just before the car passes by, all four cows hurriedly change to a four-legged stance. After the car passes by, the cows relax and revert to standing on their two hind legs.

The implication is that only when we see them, the cows are standing on four legs, but when we cannot see them, they are standing on two legs. There is no way for us to verify that they really stand on two legs when we are not looking, because the act of our looking causes them to change their stance to four legs. So we have to accept their two-legged stance as an article of faith.

Many rivers show a coarse surface layer, or armor at low flow. An example is given in Figure 1 in terms of the River Wharfe, U.K. It has often been assumed that this armor is "washed out," or at least strongly subdued, during flood flows. But it is precisely in the middle of flood flows when it is impossible to verify this hypothesis. For example in Figure 2a the Elbow River, Canada is shown at low flow; in Figure 2b it is shown at a flow estimated to be close to the 100-year flood. The Elbow River is known to be armored at low flow (Hollingshead, 1971). Is it armored at high flow, or not? Is there any way of finding out?

Some evidence suggests that the armor layer might still be present in at least some form at flood flows capable of moving most of the available sizes. For example, Parker et al. (1982) and Parker and Klingeman (1982) report experiments on gravel transport for which an armor layer was observed to be in place even under conditions of rather intense bedload transport. Andrews and Erman (1986) performed measurements in Sagehen Creek, USA during a snowmelt storm which mobilized gravel sizes coarser than the surface median size, and found that an armor layer similar to the one observed at low flow remained in place. Wilcock et al. (2001) performed experiments on mobile-bed transport of heterogeneous gravel in which the armor layer was not only present for all flows, but varied little over a wide range of flow conditions. More recently, Wilcock and DeTemple (2005) have provided an indirect indication of the persistence of an armor layer over a flood in Oak Creek. USA. They used the surface-based transport relation of Wilcock and Crowe (2003) and the measured data for bedload magnitude and size distribution of Milhous (1972) to back-calculate the surface grain size distribution. Their results indicate a surface grain size distribution that does not change as flow and transport rate increase, instead remaining essentially the same as the surface grain size distribution measured at low flow. 
So is it possible to say that gravel-bed rivers should always be armored? The answer, of course, is no. Figure 3 shows the Nahal Yatir in Israel, a gravel-bed river which is unarmored at low flow, and might be assumed to be unarmored at high flow (Powell et al., 2001). Such streams are relatively common in arid environments.

This paper is focused on the way in which a gravel-bed river adjusts to a cycled hydrograph that ranges from low flow to flood flow. The analysis is based on a 1D numerical model. It yields a fascinating conclusion: rivers can adjust over cycled hydrographs so that their surface layers become invariant to the specific discharge of the hydrograph. The conclusion is partial and tentative, because real rivers are not $1 \mathrm{D}$ entities and numerical models are less than perfect expressions of reality. If the result is borne out by more detailed field and experimental measurements, however, it has the potential to greatly simply gravel transport calculations. In particular, it implies that the surface grain size distribution to be used in a surface-based calculation of bedload transport during a flood may be approximated by the surface distribution measured at low flow (when the bed is accessible).

Or put in terms of the introductory metaphor, the cows are likely always standing on four legs, whether we are watching or not.

\section{SUMMARY OF THE CONFIGURATION AND THE ESSENTIAL RESULT}

The very simple configuration illustrated in Figure 4 is considered. The river is treated as a sediment-feed flume with constant width, vertical sidewalls and specified length. Downstream bed elevation is held constant. Water is fed into the flume at a rate that varies cyclically, so representing a repeated hydrograph including a wide range of discharges. In implementing the hydrograph, it is possible to discard flows at which bed sediment is not moved in significant amounts. A smooth hydrograph must be be discretized into steps in order for implementation in a numerical model.

Gravel (gravel/sand) is also fed into the flume at the same upstream point as the water. The software developed for the present study allows for the gravel input rate to vary cyclically in time as well. In the present implementations, however, the rate and grain size distribution of the upstream gravel (gravel/sand) are held constant.

If the above configuration is sustained for a sufficiently long time, a mobile-bed equilibrium is eventually reached. The equilibrium can strictly be defined, however, only as an average over the hydrograph. What are the characteristics of this equilibrium?

Since the input rate and grain size distribution of the feed sediment are held constant over the repeated hydrograph, one might expect that the bed cyclically degrades and coarsens during the higher flows of the hydrograph, and then aggrades and becomes finer over the lower flows of the hydrograph. The numerical results reported here suggest, however, that this behavior is limited to a very short reach downstream of the feed point. This reach may be termed a "hydrograph boundary layer," where "boundary layer" is used in 
the mathematical sense of a restricted zone over which a variable changes strongly (Nayfeh, 1993). Downstream of this hydrograph boundary layer a remarkable tradeoff occurs. Bed slope and bed surface grain size distribution become essentially invariant with discharge on the hydrograph (and thus time) and distance downstream. Instead, the magnitude and grain size distribution of the bedload vary cyclically with position on the hydrograph (but do not vary with distance downstream).

\section{QUANTIFICATION OF THE CONFIGURATION}

Again the very simple configuration illustrated in Figure 4 is considered. The river has constant width B, no floodplain, vertical sidewalls and constant length $\mathrm{L}$. Sidewall effects are neglected for simplicity. The downstream bed elevation $\eta$ is fixed at 0 ; thus where $\mathrm{x}$ denotes streamwise distance from the sediment feed point,

$$
\left.\eta\right|_{x=L}=0
$$

Water is introduced to the flume at the upstream end $(x=0)$ at flow discharge $Q_{w}(t)$, where $t$ denotes time. Here $\mathrm{Q}_{\mathrm{w}}(\mathrm{t})$ is allowed to vary cyclically so as to simulate a periodic hydrograph.

The river is assumed to be sufficiently steep and the reach sufficiently short so that flood waves traverse the reach in a time that is very short compared to the characteristic time of morphodynamic evolution. As a result, all flows can be accurately described using the normal (steady, uniform) approximation, with the discharge at any point in the flow (nearly) instantaneously adjusting to the upstream value $\mathrm{Q}_{\mathrm{w}}(\mathrm{t})$. This assumption is often reasonable for reaches of mountain gravel-bed rivers not longer than a few 10's of km.

A heterogeneous mixture of gravel (or gravel and sand) that moves as bedload is also fed in at the upstream end of the flume. For simplicity, this is assumed to be fed in at a constant rate, and to have a constant feed grain size distribution. Consider $\mathrm{N}$ grain size bins $\mathrm{i}=1 . . \mathrm{N}$, each with characteristic size $\mathrm{D}_{\mathrm{i}}$. Let $\mathrm{q}_{\mathrm{bi}}$ denote the volume bedload transport rate per unit width in the ith grain size range. The total volume bedload transport rate per unit width summed over all grain sizes is given as

$$
\mathrm{q}_{\mathrm{bT}}=\sum_{\mathrm{i}=1}^{\mathrm{N}} \mathrm{q}_{\mathrm{bi}}
$$

The volume fraction of bedload in the ith grain size range is denoted as

$$
\mathrm{p}_{\mathrm{bi}}=\frac{\mathrm{q}_{\mathrm{bi}}}{\mathrm{q}_{\mathrm{bT}}}
$$

The feed values of $\mathrm{q}_{\mathrm{bi}}, \mathrm{q}_{\mathrm{bT}}$ and $\mathrm{p}_{\mathrm{bi}}$ are denoted respectively as $\mathrm{q}_{\mathrm{bfi}}$, $\mathrm{q}_{\mathrm{bfT}}$ and $\mathrm{p}_{\mathrm{fi}}$, such that

$$
\left.\mathrm{q}_{\mathrm{bi}}\right|_{\mathrm{x}=0}=\mathrm{q}_{\mathrm{bfi}},\left.\mathrm{q}_{\mathrm{bT}}\right|_{\mathrm{x}=0}=\mathrm{q}_{\mathrm{bTf}},\left.\mathrm{p}_{\mathrm{bi}}\right|_{\mathrm{x}=0}=\mathrm{p}_{\mathrm{bfi}} \quad \text { (4a,b,c) }
$$

Here these feed values are held constant over the hydrograph. That is, in a given numerical experiment the magnitude and grain size distribution of the sediment feed are held constant, even though the water discharge is varying cyclically.

\section{EXNER EQUATION OF SEDIMENT CONSERVATION}


The Exner equation of sediment conservation for mixtures used here is that of Parker and Sutherland (1990). The bed is divided into an upper "active" ("surface", "exchange") layer and a lower substrate. The active layer consists of the gravel that exchanges directly with bedload transport. The active layer exchanges sediment with the substrate as the bed aggrades (transfer from active layer to substrate) or degrades (transfer from substrate to active layer).

As noted in Figure 4, the active layer has thickness $L_{a}(x, t)$, the notation indicating that thickness may vary in both time and distance downstream. The volume fraction of material in the ith grain size range in the active layer, or surface fraction $F_{i}$ may also vary in $\mathrm{x}$ and $\mathrm{t}$, but the active layer is approximated as having no vertical structure. As the bed aggrades or degrades, the fraction in the ith grain size range exchanged at the interface between the bottom of the surface layer and the top of the substrate is denoted as $\mathrm{f}_{\mathrm{Ii}}$. Denoting bed porosity as $\lambda_{\mathrm{p}}$, the grain size-specific Exner equation of sediment continuity takes the form

$$
\left(1-\lambda_{p}\right)\left[f_{\text {Ii }} \frac{\partial}{\partial t}\left(\eta-L_{a}\right)+\frac{\partial}{\partial t}\left(F_{i} L_{a}\right)\right]=-\frac{\partial q_{b i}}{\partial x}
$$

Summing the above equation over all grain sizes and recalling that

$$
\sum_{\mathrm{i}=1}^{\mathrm{N}} \mathrm{F}_{\mathrm{i}}=\sum_{\mathrm{i}=1}^{\mathrm{N}} \mathrm{f}_{\mathrm{Ii}}=1
$$

it is found that

$$
\left(1-\lambda_{\mathrm{p}}\right) \frac{\partial \eta}{\partial \mathrm{t}}=-\frac{\partial \mathrm{q}_{\mathrm{bT}}}{\partial \mathrm{x}}
$$

Reducing (4) with (6) results in the relation

$$
\left(1-\lambda_{\mathrm{p}}\right)\left[\mathrm{L}_{\mathrm{a}} \frac{\partial \mathrm{F}_{\mathrm{i}}}{\partial \mathrm{t}}+\left(\mathrm{F}_{\mathrm{i}}-\mathrm{f}_{\mathrm{Ii}}\right) \frac{\partial \mathrm{L}_{\mathrm{a}}}{\partial \mathrm{t}}\right]=\mathrm{f}_{\mathrm{Ii}} \frac{\partial \mathrm{q}_{\mathrm{bT}}}{\partial \mathrm{x}}-\frac{\partial \mathrm{q}_{\mathrm{bi}}}{\partial \mathrm{x}}
$$

Thus (6) describes the evolution of bed elevation and (7) describes the evolution of the surface grain size distribution.

In implementing the above equation it is necessary to specify the thickness $\mathrm{L}_{\mathrm{a}}$ of the active layer and the interfacial exchange fractions $\mathrm{f}_{\mathrm{Ii}}$. Here the thickness of the active layer is specified as an order-one multiple of the surface size $D_{\text {s90 }}$ such that 90 percent of the sediment is finer:

$$
\mathrm{L}_{\mathrm{a}}=\mathrm{n}_{\mathrm{a}} \mathrm{D}_{\mathrm{s} 90}
$$

where $\mathrm{n}_{\mathrm{a}}$ is an order-one dimensionless parameter. The interfacial fractions are specified as follows. The substrate is likely to contain its own stratigraphy, so that substrate fractions $\mathrm{f}_{\mathrm{i}}$ vary with vertical distance $\mathrm{z}$ (in addition to $\mathrm{x}$ ). As the bed degrades, the substrate just below it is mined into the active layer. As the bed aggrades, some mixture of bedload and active layer material is transferred to the substrate. Thus

$$
\mathrm{f}_{\mathrm{Ii}}=\left\{\begin{array}{c}
\left.\mathrm{f}_{\mathrm{i}}\right|_{\mathrm{z}=\eta-\mathrm{L}_{\mathrm{a}}}, \frac{\partial \eta}{\partial \mathrm{t}}<0 \\
\alpha \mathrm{F}_{\mathrm{i}}+(1-\alpha) \mathrm{p}_{\mathrm{bi}}, \frac{\partial \eta}{\partial \mathrm{t}}>0
\end{array}\right.
$$


where $\alpha$ is a specified parameter between 0 and 1 (Hoey and Ferguson, 1994; ToroEscobar et al., 1996).

\section{FLOW HYDRAULICS}

The flow hydraulics is computed using a simple normal (steady, uniform) flow approximation that is often suitable for mountain streams. Water discharge $\mathrm{Q}_{\mathrm{w}}$ is related to water discharge per unit width $\mathrm{q}_{\mathrm{w}}$, flow depth $\mathrm{H}$ and depth-averaged flow velocity $\mathrm{U}$ as

$$
\mathrm{Q}_{\mathrm{w}}=\mathrm{q}_{\mathrm{w}} \mathrm{B}=\mathrm{UHB}
$$

The Manning-Strickler relation of Parker (1990) is used to compute flow resistance;

$$
\frac{\mathrm{U}}{\mathrm{u}_{*}}=\mathrm{C}_{\mathrm{f}}^{-1 / 2}=\alpha_{\mathrm{r}}\left(\frac{\mathrm{H}}{\mathrm{k}_{\mathrm{s}}}\right)^{1 / 6}
$$

In the above relation $C_{f}$ is a dimensionless bed friction coefficient, $\alpha_{r}$ takes a value of 8.1, $\mathrm{k}_{\mathrm{s}}$ denotes a roughness height, related here to surface size $\mathrm{D}_{\mathrm{s} 90}$ as

$$
\mathrm{k}_{\mathrm{s}}=\mathrm{n}_{\mathrm{k}} \mathrm{D}_{\mathrm{s} 90}
$$

where $\mathrm{n}_{\mathrm{k}}$ is another order-one coefficient here set equal to 2 and $\mathrm{u}_{*}$ denotes a shear velocity, related to bed shear stress $\tau_{\mathrm{b}}$ as

$$
\tau_{\mathrm{b}}=\rho \mathrm{u}_{*}^{2}
$$

where $\rho$ denotes water density. In the present analysis all resistance is assumed to be skin friction; form drag is neglected for simplicity.

According to the normal flow approximation, $\tau_{\mathrm{b}}$ is related to the depth-slope product as

$$
\tau_{\mathrm{b}}=\rho g H S
$$

where S denotes bed slope. Between (10), (11), (13) and (14) it is found that the shear velocity $\mathrm{u}_{*}$ can be computed from the local bed slope $\mathrm{S}$ and local roughness height $\mathrm{k}_{\mathrm{s}}$ (and the water discharge per unit width $\mathrm{q}_{\mathrm{w}}$, which varies in time but not space) as

$$
\mathrm{u}_{*}(\mathrm{x}, \mathrm{t})=\alpha_{\mathrm{r}}^{-3 / 10} \mathrm{~g}^{7 / 20}\left[\mathrm{q}_{\mathrm{w}}(\mathrm{t})\right]^{3 / 10}\left[\mathrm{k}_{\mathrm{s}}(\mathrm{x}, \mathrm{t})\right]^{1 / 20} \mathrm{~S}(\mathrm{x}, \mathrm{t})^{7 / 20}
$$

Note that the above equation is dimensionally homogeneous.

\section{SURFACE-BASED BEDLOAD TRANSPORT FORMULATION}

The analysis presented here is restricted to the case of bedload transport of either gravel, or gravel with some admixture of sand. In order to compute the evolution of the fractions $F_{i}$ in the surface (active, exchange) layer as the bed evolves, it is necessary to tie the bedload transport rate of the ith size range to the availability of this size range in the surface layer. Several formulae are presently available to do this, including Parker (1990), Powell et al. (2001), Hunziker and Jaeggi (2002) and Wilcock and Crowe (2003). Here calculations are performed with the relation of Wilcock and Crowe (2003). It should be pointed out, however, that calculations with the relation of Parker (1990)

illustrate that the essential conclusions of the analysis are independent of the specific bedload formulation used. 
All of the above bedload transport relations can be cast in a form such that they predict a dimensionless bedload transport rate $\mathrm{W}_{\mathrm{i}}^{*}$ for the ith grain size range, which is related to the volume transport rate per unit width $\mathrm{q}_{\mathrm{bi}}$ as

$$
\mathrm{q}_{\mathrm{bi}}=\mathrm{F}_{\mathrm{i}} \frac{\mathrm{u}_{*}^{3}}{\operatorname{Rg}} \mathrm{W}_{\mathrm{i}}^{*}
$$

where $\mathrm{R}$ denotes the submerged specific gravity of the sediment, given as

$$
\mathrm{R}=\frac{\rho_{\mathrm{s}}}{\rho}-1
$$

and $\rho_{\mathrm{s}}$ denotes the material density of the sediment. For natural sediments $\mathrm{R}$ is often close to 1.65. Details of the relation of Wilcock and Crowe (2003) are not presented here; these can be found in the original reference and Parker (2004). Instead, brief summaries of input parameters are given.

In the case of the relation of Wilcock and Crowe (2003), in order to compute $\mathrm{W}_{\mathrm{i}}^{*}$ it is necessary to know a) the shear velocity $\mathrm{u}_{*}, \mathrm{~b}$ ) the submerged specific gravity of the sediment $R, c)$ the surface grain sizes and fractions $\left(D_{i}, F_{i}\right)$ and d) the surface geometric mean size $D_{s g}$ and the fraction of sand $F_{s}$ in the surface layer, both of which can be computed from $\left(\mathrm{D}_{\mathrm{i}}, \mathrm{F}_{\mathrm{i}}\right)$. Note that sand is specifically included, and that varied sand content in the surface layer can have a strong effect on the transport rate of gravel-sized material.

\section{FLOW OF THE CALCULATION}

In order to perform a calculation, the following dimensionless parameters must be specified in advance: bed porosity $\lambda_{p}$, coefficient $n_{a}$ in (8) describing active layer thickness, coefficient $\alpha$ describing transfer to the substrate as the bed aggrades, coefficient $\alpha_{r}$ in the resistance relation (11), coefficient $n_{k}$ in the relation for the roughness height (12) and the submerged specific gravity R of the sediment. In addition, the characteristic grain sizes $D_{i}, i=1$..N must be specified. Finally, the cyclic variation of water discharge per unit width with time $\mathrm{q}_{\mathrm{w}}(\mathrm{t})$ must be specified.

The flow of the calculation is as follows. At any given time $t$ the bed profile $\eta(x, t)$, and surface fractions $\mathrm{F}_{\mathrm{i}}(\mathrm{x}, \mathrm{t})$ are taken to be known. Bed slope $\mathrm{S}$ is computed as

$$
S=-\frac{\partial \eta}{\partial x}
$$

The surface fractions $F_{i}$ are used to compute $D_{s 90}, D_{s g}, F_{s}$ everywhere. $L_{a}$ and $k_{s}$ are everywhere computed from (8) and (12), respectively. Shear velocity $\mathrm{u}_{*}(\mathrm{x}, \mathrm{t})$ is then computed everywhere from (15). A knowledge of $\mathrm{u}_{*}, \mathrm{D}_{\mathrm{s} 90}, \mathrm{D}_{\mathrm{sg}}, \mathrm{F}_{\mathrm{s}}$ allows computation of $\mathrm{W}_{\mathrm{i}}^{*}$ from the relation of Wilcock and Crowe (2003), and thus $\mathrm{q}_{\mathrm{bi}}(\mathrm{x}, \mathrm{t})$ everywhere from (16). The parameters $\mathrm{q}_{\mathrm{bT}}$ and $\mathrm{p}_{\mathrm{bi}}$ are then computed from (2) and (3).

The bed elevation profile one time step later, i.e. at time $t+\Delta t$, is then computed from a discretized version of (6), i.e. 


$$
\eta(x, t+\Delta t)=\eta(x, t)-\frac{1}{\left(1-\lambda_{p}\right)} \frac{\partial q_{b T}}{\partial x} \Delta t
$$

Equation (6) also directly estimates $\partial \eta / \partial t$;

$$
\left.\frac{\partial \eta}{\partial \mathrm{t}}\right|_{\mathrm{t}}=-\left.\frac{1}{1-\lambda_{\mathrm{p}}} \frac{\partial \mathrm{q}_{\mathrm{bT}}}{\partial \mathrm{x}}\right|_{\mathrm{t}}
$$

which then allows evaluation of $f_{\text {Ii }}$ everywhere from (9). The surface fractions one time step later are then evaluated from (7) as

$$
\left.\mathrm{F}_{\mathrm{a}}\right|_{\mathrm{t}+\Delta \mathrm{t}}=\left.\mathrm{F}_{\mathrm{a}}\right|_{\mathrm{t}}+\left[\frac{1}{\left(1-\lambda_{\mathrm{p}}\right) \mathrm{L}_{\mathrm{a}}}\left(\mathrm{f}_{\mathrm{Ii}} \frac{\partial \mathrm{q}_{\mathrm{bT}}}{\partial \mathrm{x}}-\frac{\partial \mathrm{q}_{\mathrm{bi}}}{\partial \mathrm{x}}\right)-\frac{\left(\mathrm{F}_{\mathrm{i}}-\mathrm{f}_{\mathrm{Ii}}\right)}{\mathrm{L}_{\mathrm{a}}} \frac{\partial \mathrm{L}_{\mathrm{a}}}{\partial \mathrm{t}}\right] \Delta \mathrm{t}
$$

In principle (21) requires an iterative solution due to the presence of the term $\partial \mathrm{L}_{\mathrm{a}} / \partial \mathrm{t}$, but this term is typically small, and can usually be evaluated from the previous time step.

The boundary conditions on the above formulation are (1), which specifies a fixed downstream bed elevation, and (4a,b), which specify a fixed feed rate and feed grain size distribution of sediment. The initial conditions consist of a specified initial bed slope, and specified initial grain size distributions for the bed surface and substrate.

The reach of length $L$ is discretized into $M$ intervals, each with length $\Delta x=L / M$, bounded by $M+1$ nodes. The node $k=1$ denotes the node farthest upstream and the node $\mathrm{k}=\mathrm{M}+1$ denotes the node farthest downstream. Sediment is fed in at a ghost node one step upstream of the node $\mathrm{k}=1$.

Spatial derivatives involving sediment transport parameters ( $\left.\mathrm{q}_{\mathrm{bT}}, \mathrm{q}_{\mathrm{bi}}\right)$ are computed using an upwinding scheme, e.g. at the kth node,

$$
\left.\frac{\partial \mathrm{q}_{\mathrm{bT}}}{\partial \mathrm{x}}\right|_{\mathrm{k}}=\mathrm{a}_{\mathrm{u}} \frac{\mathrm{q}_{\mathrm{bT}, \mathrm{k}}-\mathrm{q}_{\mathrm{bT}, \mathrm{k}-1}}{\Delta \mathrm{x}}+\left(1-\mathrm{a}_{\mathrm{u}}\right) \frac{\mathrm{q}_{\mathrm{bT}, \mathrm{k}+1}-\mathrm{q}_{\mathrm{bT}, \mathrm{k}}}{\Delta \mathrm{x}}
$$

In the above relation $\mathrm{a}_{\mathrm{u}}$ is an upwinding coefficient. A value of $\mathrm{a}_{\mathrm{u}}$ of 0.5 corresponds to $\mathrm{a}$ central difference scheme, and a value of $a_{u}$ satisfying the conditions $0.5<a_{u} \leq 1$ corresponds to an upwinded scheme.

\section{OUTLINE OF AND INPUT FOR THE NUMERICAL RUNS}

Numerical runs are performed for both a cycled hydrograph and a constant flow corresponding to the average of that hydrograph. The hydrograph chosen for implementation is a discretization of a 4.5-day symmetrical triangular hydrograph with a beginning and end flow discharge per unit width of $2 \mathrm{~m}^{2} / \mathrm{s}$ and a maximum flow

discharge per unit width of $20 \mathrm{~m}^{2} / \mathrm{s}$. The average flow of the hydrograph is $10 \mathrm{~m}^{2} / \mathrm{s}$. The hydrograph and its average flow are shown in Figure 5. The hydrograph (or its equivalent constant flow) is run once per year for 4.5 days. The river is taken to be morphologically inactive for the rest of the year.

The sediment feed is taken to be the bimodal mix of gravel and sand given Figure 6. This distribution has median size $\mathrm{D}_{150 \mathrm{f}}(\mathrm{l}=$ load, 50 = median, $\mathrm{f}=$ feed $)$ of $32 \mathrm{~mm}$, a geometric mean size $\mathrm{D}_{\text {lgf }}(\mathrm{l}=$ load, $\mathrm{g}=$ geometric mean, $\mathrm{f}=$ feed $)$ of $16.22 \mathrm{~mm}$ and a fraction of 
sand $F_{\text {slf }}(s=$ sand, $l=$ load,$f=$ feed $)$ of 0.25 . The initial surface and substrate size distributions at $\mathrm{t}=0$ are taken to be identical to that of the feed sediment.

The following parameters are specified in the calculation as follows: $\mathrm{R}=1.65, \mathrm{n}_{\mathrm{a}}=2, \mathrm{n}_{\mathrm{k}}$ $=2, \lambda_{\mathrm{p}}=0.4, \alpha_{\mathrm{r}}=8.1, \alpha=0.5, \mathrm{a}_{\mathrm{u}}=0.75$. The initial bed slope is a constant specified value. This value was chosen to be not too far from the expected value in order to minimize the amount of computational time to reach a final mobile-bed equilibrium. In all numerical experiments $L=20,000 \mathrm{~m}$ and $M=20$, so that $\Delta x=1000 \mathrm{~m}$.

Eleven runs, i.e. Runs $1 \mathrm{H}, 2 \mathrm{H}, 3 \mathrm{H} \ldots 11 \mathrm{H}$ were conducted with the hydrograph of Figure 5. Eleven more runs, i.e. 1C, 2C, 3C... 11C were conducted with the average flow of the hydrograph also shown in Figure 5 . The input parameters are specified in Table 1 (hydrograph runs) and Table 2 (constant-flow runs). It is seen there that sediment feed rates $q_{\mathrm{bTf}}$ vary over a wide range, from $1 \times 10^{-6} \mathrm{~m}^{2} / \mathrm{s}$ to $1 \times 10^{-1} \mathrm{~m}^{2} \mathrm{~s}$. Also shown in the Table 1 are initial bed slope $S_{\text {I }}$, time step during a flood $\Delta t_{f}$, number of time steps per step on the flow hydrograph (during the flood) $\mathrm{n}_{\text {step }}$ and time duration $\mathrm{T}_{\text {dur }}$ of the calculation. Also shown in Table 2 are $S_{\mathrm{I}}, \mathrm{T}_{\text {dur }}$ and time step $\Delta \mathrm{t}$ (real time including flood time and inactive time).

\section{RESULTS FOR CONSTANT FLOW AT MOBILE-BED EQUILIBRIUM}

Before analyzing the case of a hydrograph, it is of value to briefly discuss the results for the equivalent constant flows. The results analyzed here are for the 11 runs of Table 2. Recall that water discharge per unit width is held at $10 \mathrm{~m}^{2} / \mathrm{s}$ for 4.5 days of the year for all runs, but that the sediment feed $q_{b T f}$ rate varies from a high rate of $1 \times 10^{-1} \mathrm{~m}^{2} / \mathrm{s}$ for Run $1 \mathrm{C}$ to a low of $1 \times 10^{-6} \mathrm{~m}^{2} / \mathrm{s}$ for Run $11 \mathrm{C}$.

Figure 7 shows plots of the following three parameters versus sediment feed rate $\mathrm{q}_{\mathrm{bTf}}$ at final, mobile-bed equilibrium; bed slope $S$, surface geometric mean size $D_{\text {sg }}$ and geometric mean size of the feed sediment $\mathrm{D}_{\text {lgf. }}$. Note that the feed rate $\mathrm{q}_{\mathrm{bTf}}$ is everywhere equal to the transport rate $\mathrm{q}_{\mathrm{bT}}$ in the case of mobile-bed equilibrium at constant flow.

The diagram shows that bed slope $S$ increases, and surface geometric mean size $D_{s g}$ decreases with increasing $\mathrm{q}_{\mathrm{bTf}}$. At very low values of $\mathrm{q}_{\mathrm{bTf}}$ the bed approaches a static armor, and $S$ and $D_{\text {sg }}$ show values near 0.0013 and $100 \mathrm{~mm}$, respectively, that change only weakly with $\mathrm{q}_{\mathrm{bTf}}$. $\mathrm{S}$ increases ever more sharply with higher values of $\mathrm{q}_{\mathrm{bTf}}$, reaching a value near 0.026 for $q_{\mathrm{bTf}}=0.1 \mathrm{~m}^{2} / \mathrm{s}$. Likewise, the surface geometric mean size $\mathrm{D}_{\mathrm{sg}}$ decreases toward the geometric mean of the feed sediment at high value of $\mathrm{q}_{\mathrm{bTf}}$, indicating that the surface layer is approaching an unarmored state compared to the sediment transported. In between these two limits is a wide range for which a) the bed is armored under mobile-bed conditions, and b) the geometric mean size of the armor gradually becomes finer with increasing $\mathrm{q}_{\mathrm{bTf}}$. This result suggests that a mobile-bed armor might be expected under flood conditions prevailing in a stream such as the River Wharfe (Figure 1), which likely has modest gravel supply, but might be absent under 
flood conditions in a stream such as the Nahal Yatir (Figure 3), which has an extremely high gravel supply (Powell et al., 2001).

In Figure 8 the fraction of sand in the surface layer $F_{s s}$ (first $s=$ sand, second $s=$ surface) and the fraction of sand in the bedload feed material feed $\mathrm{F}_{\text {slf }}(\mathrm{s}=$ sand, $\mathrm{l}=$ load, $\mathrm{f}=$ feed) are plotted against $\mathrm{q}_{\mathrm{bTf}}$. (The plot shows percentages rather than fractions.) The percentage sand in the feed $\mathrm{F}_{\text {slf }}$ has been held constant at 25 percent for all runs. At the lowest feed rate $\mathrm{q}_{\mathrm{bTf}}$ of $1 \times 10^{-6} \mathrm{~m}^{2} / \mathrm{s}$ the surface layer contains only 0.56 percent sand. The percentage of sand in the surface layer rises with increasing $\mathrm{q}_{\mathrm{bTf}}$, until at the highest feed rate $\mathrm{q}_{\mathrm{b} T f}$ a value of 19 percent is attained. Thus sand is nearly absent from the surface layer at sediment transport rates rates low enough to correspond to a nearly static armor, even though the load is 25 percent sand. When the sediment transport is sufficiently high, the percent sand in the surface layer approaches that of the load (nearly unarmored). In between is a range of mobile armor for which sand is present in the surface layer, but at a noticeably lower percentage than in the load.

Figure 9 shows the grain size distributions for the feed, and for the surface layer at mobile-bed equilibrium for all 11 runs of Table 2. The progression with increasing feed rate $\mathrm{q}_{\mathrm{bTf}}$ from nearly static armor to mobile armor, and then to a state for which the bed is nearly unarmored is readily apparent from the figure.

\section{RESULTS FOR CYCLED HYDROGRAPHS: FORMATION AND SIGNIFICANCE OF THE HYDROGRAPH BOUNDARY LAYER}

The 11 runs with cycled hydrographs are those summarized in Table 1 . Before discussing the results of the numerical modelling, however, it is important to review the constraints on the experiments.

In every numerical run an identical hydrograph (that of Figure 5) is repeated once annually for hundreds to hundreds of thousands of years until a mobile-bed equilibrium state is reached. In each numerical run the sediment feed rate $\mathrm{q}_{\mathrm{bTf}}$ is held constant over the hydrograph. This constant feed rate varied from $1 \times 10^{-1} \mathrm{~m}^{2} / \mathrm{s}$ in Run $1 \mathrm{H}$ to $1 \times 10^{-6} \mathrm{~m}^{2} / \mathrm{s}$ in Run $11 \mathrm{H}$.

Because of this configuration, a mobile-bed equilibrium cannot consist of a constant state. Instead, it must consist of a state in which exactly the same cycle is repeated over and over. Now what might this cycling equilibrium consist of?

At the very upstream end, water discharge fluctuates up and down, but the sediment feed rate and grain size distribution are held constant. As a result, one might expect the bed to cyclically a) degrade and coarsen at the high flows, when the transport capacity exceeds the feed rate, and b) aggrade and become finer at the low flows, when the transport capacity is less than the feed rate.

The numerical runs reveal, however, a fascinating result. The above, "expected" behavior is realized only in a relatively short hydrograph boundary layer downstream of 
the feed point. Downstream of this hydrograph boundary layer a tradeoff takes place. The mobile-bed equilibrium consists of a bed which no longer cycles even though flow discharge continues to cycle. That is, bed elevation and surface grain size distribution remain constant in time over the hydrograph. Instead, the cycling is transferred to the bedload transport rate and bedload grain size distribution. The bedload transport rate cyclically increases, and the bedload becomes coarser at the high flows of the hydrograph, and the pattern is reversed at the low flows of the hydrograph.

This pattern is illustrated schematically in Figure 10. In that figure, bed elevation is shown to vary cyclically only in a short hydrograph boundary layer near the feed point. Within this boundary layer bed elevation $\eta$ and surface geometric mean size $D_{s g}$ fluctuate over the hydrograph in response to changing water discharge $\mathrm{q}_{\mathrm{w}}$ but constant sediment feed rate $\mathrm{q}_{\mathrm{bTf}}$ and constant feed grain size distribution (e.g. constant feed geometric mean size $D_{\text {lgf, }}$ where $\mathrm{l}=$ load, $\mathrm{g}=$ geometric mean, $\mathrm{f}=$ feed). Downstream of this boundary layer, over a region that consists of the great majority of the total modelled reach, bed elevation $\eta$ and surface geometric mean size $D_{s g}$ remain constant over the hydrograph, but the bedload transport rate $\mathrm{q}_{\mathrm{bт}}$ and size distribution (e.g. load geometric mean size $\mathrm{D}_{\mathrm{lg}}$ ) fluctuate cyclically over the hydrograph.

Numerical results for two numerical runs, Run $3 \mathrm{H}\left(\mathrm{q}_{\mathrm{bTf}}=1 \mathrm{x} 10^{-2} \mathrm{~m}^{2} / \mathrm{s}\right)$ and Run $6 \mathrm{H}\left(\mathrm{q}_{\mathrm{bTf}}\right.$ $=3.5 \times 10^{-4} \mathrm{~m}^{2} / \mathrm{s}$ ) are sufficiently characteristic to warrant their use in justifying the above conclusions. Run $3 \mathrm{H}$ is considered first. Figure 11 shows a plot of the streamwise variation of bed slope at the maximum (peak) flow and the minimum (end) flow of the last hydrograph of the experiment, well after mobile-bed equilibrium had been reached. Bed slope $S$ is identical at the peak and end flows of the hydrograph at all points except those within about $4000 \mathrm{~m}$ of the feed point. In this hydrograph boundary layer reach, bed slope is low at the peak flow and high at the low flow, as the bed responds to a fluctuating flow discharge but a constant feed rate. No such adjustment is observed downstream of this short boundary layer reach.

Not only does bed slope $\mathrm{S}$ become invariant downstream of the hydrograph boundary layer reach, but also surface geometric mean size $D_{\text {sg }}$ no longer varies with the hydrograph. This is illustrated in Figure 12, which shows the grain size distributions of the surface layer at both the maximum (peak) and minimum (end) flow of the last hydrograph of the experiment. The two surface size distributions overlap each other so closely that they are virtually identical. The results for Figure 12 pertain to the node at the end of the model reach $(k=21)$, where $x=L$. The same invariance in the surface grain size distribution is also found farther upstream, as long as the point in question is downstream of the hydrograph boundary layer of Figure 11.

Figure 12 illustrates the tradeoff between fluctuations in surface size distribution and load size distribution downstream of the hydrograph boundary layer reach. In addition to surface size distributions, the plot shows the size distribution of the load at the maximum (peak) flow and minimum (end) flow of the last hydrograph of the experiment, the load distribution averaged over the last hydrograph and finally the size distribution of the feed sediment. The node in question is again the farthest node downstream. The grain size 
distribution of the load averaged over the hydrograph is very close to that of the feed, as is to be expected at mobile-bed equilibrium. The load size distribution at the maximum (peak) flow is somewhat coarser than the feed sediment, and the load size distribution at the minimum (end) flow is markedly finer. That is, the grain size distribution of the load now fluctuates markedly with the hydrograph, even as the grain size distribution of the surface layer remains invariant. Again, the same result is obtained farther upstream at any point downstream of the hydrograph boundary layer reach.

Figure 13a shows the variation in water discharge per unit width $\mathrm{q}_{\mathrm{w}}$, volume sediment transport rate per unit width $\mathrm{q}_{\mathrm{b}}$ and bed slope $\mathrm{S}$ over the last hydrograph of the run. Again, the plot pertains to the node farthest downstream, and again essentially the same results are obtained at all points downstream of the hydrograph boundary layer. Note that bed slope $S$ remains nearly perfectly constant over the hydrograph. The sediment transport rate $\mathrm{q}_{\mathrm{b}}$, however, fluctuates strongly in concordance with the hydrograph; high flows cause high bedload rates, and low flow causes low bedload transport rates.

Figure 13b has the same format as Figure 13a, but the point in question is the first node upstream $(\mathrm{k}=1 ; \mathrm{x}=0)$, just downstream of the ghost node where sediment is fed in. This node is well within the hydrograph boundary layer reach, as is seen from Figure 11; bed slope $\mathrm{S}$ fluctuates cyclically as the channel tries to adjust to a constant sediment supply but cyclic water discharge variation. Also plotted in Figure $13 \mathrm{~b}$ is the variation of load $\mathrm{q}_{\mathrm{bT}}$ over the hydrograph. Note that $\mathrm{q}_{\mathrm{bT}}$ is already varying cyclically over the hydrograph at the first node upstream, even though the pattern is rather strongly skewed as compared to that in Figure 13a.

Figure 14a shows the variation of $\mathrm{q}_{\mathrm{w}}$, load geometric mean size $\mathrm{D}_{\mathrm{lg}}$ and surface geometric mean size $D_{s g}$ at the farthest node downstream $(M=21)$ over the last hydrograph of the numerical run. The corresponding plot for the farthest node upstream $(\mathrm{M}=1)$ is given in Figure 14b. Comparing the two figures, it is seen that surface geometric mean $\mathrm{D}_{\mathrm{sg}}$ grain size varies cyclically at the upstream node, but shows little variation at the downstream node. The load geometric mean grain size varies cyclically at both nodes, but the variation is stronger at the downstream node.

The essential points are worth summarizing again. A hydrograph is cycled repeatedly. Sediment is fed in at the upstream end at a constant rate and with a constant grain size distribution. Within a short hydrograph boundary layer near the feed, the mobile-bed equilibrium associated with these constraints consists of a bed elevation, bed slope and surface size distribution that fluctuate cyclically with the hydrograph. Farther downstream, however, bed elevation, bed slope and surface size distribution evolve to become independent of the hydrograph, and instead the cyclic variation is transferred to the magnitude and grain size distribution of the bedload transport.

The above summary also implies the conditions under which the hydrograph boundary layer disappears. Suppose that the run were to be continued at mobile-bed equilibrium, but the bedload feed rate and size distribution were now allowed to fluctuate cyclically and sympathetically with the hydrograph, in precisely the way that is observed 
downstream of the hydrograph boundary layer. Under such conditions the hydrograph boundary layer would disappear, and the bed elevation and surface size distribution would everywhere become constant over the hydrograph, even inside what used to be the hydrograph boundary layer. The above statement is easily confirmed with the numerical model.

All 11 numerical runs indicate that, other factors being equal, the length of the hydrograph boundary layer increases with increasing sediment feed rate $\mathrm{q}_{\mathrm{bTf}}$. With this in mind, results are also shown for Run $6 \mathrm{H}\left(\mathrm{q}_{\mathrm{b} T \mathrm{ff}}=3.5 \times 10^{-4} \mathrm{~m}^{2} / \mathrm{s}\right)$. Figure 15 for Run $6 \mathrm{H}$ shows the slope profiles at the maximum (peak) and minimum (end) flows of the last hydrograph of the run. Again, the node is the one farthest downstream. The hydrograph boundary layer is again clearly apparent, although the phasing of aggradation is different from that seen in Figure 11 for Run 3H. Figure 16 for Run $6 \mathrm{H}$, which corresponds to Figure 12 for Run $3 \mathrm{H}$, again shows that the invariance of the surface grain size distributions over the hydrograph at the last node, even while the grain size distribution of the load varies strongly between the maximum (peak) and minimum (end) flows of the last hydrograph.

Figures 17a and 17b for Run 6H, which correspond to Figure 13a for Run 3H, show that at the node farthest downstream the bedload transport rate varies strongly over the hydrograph at mobile-bed equilibrium, whereas bed slope remains constant. Figures 17c and $17 \mathrm{~d}$ for Run $6 \mathrm{H}$, which correspond to Figure $13 \mathrm{~b}$ for Run $3 \mathrm{H}$, show that both the bedload transport rate and the bed slope vary over the hydrograph at the node farthest upstream. A comparison of Figures $13 \mathrm{~b}$ and $17 \mathrm{~d}$ show that a phase shift in bed slope variation at $\mathrm{x}=0$ of about half a day in Run $6 \mathrm{H}$ as compared to Run $3 \mathrm{H}$, such that bed slope attains its maximum and minimum values at later times in Run $6 \mathrm{H}$ than in Run $3 \mathrm{H}$.

Figures 18a and $18 \mathrm{~b}$ for Run $6 \mathrm{H}$, which corresponding to Figures 14a and 14b for Run $3 \mathrm{H}$, illustrate a surface geometric mean size that remains nearly perfectly constant over the hydrograph at the downstream node, but which shows marked cyclic variation at the upstream node.

Summarizing, Run $6 \mathrm{H}$ shows all the features of Run $3 \mathrm{H}$, but more strongly so. For example, it is of value to compare Figure 18a of Run $6 \mathrm{H}$ with Figure 14a of Run 3H. In both cases it is seen that the surface geometric mean size $D_{s g}$ at the node farthest downstream shows little cyclic variation at mobile-bed equilibrium. Some variation is, however detectable in the case of Figure 14a for Run $3 \mathrm{H}$, where the variation is undetectable in the case of Figure 18a for Run 6H. This reflects the tendency for the effect of the upstream boundary conditions to become ever more strongly concentrated in an ever-thinner hydrograph boundary layer reach as $\mathrm{q}_{\mathrm{bTf}}$ declines.

\section{COMPARISON OF RESULTS FOR CONSTANT FLOW VERSUS CYCLED HYDROGRAPH}

In the figures discussed below the morphodynamic behavior of the river outside the hydrograph boundary layer at mobile-bed equlibrium is characterized by the behavior at 
the node farthest downstream. This is because at mobile-bed equilibrium the behavior outside the hydrograph boundary layer is, to a high degree of approximation, everywhere the same as that at the node farthest downstream.

Figure 19 shows plots of the following parameters at mobile-bed equilibrium against sediment feed rate $\mathrm{q}_{\mathrm{bTf}}$ for the 11 runs with a cycled hydrograph: surface geometric mean size averaged over the hydrograph $\mathrm{D}_{\text {sga }}$, bedload geometric mean size averaged over the hydrograph $\mathrm{D}_{\text {lga }}$, geometric mean size of the feed sediment $\mathrm{D}_{\text {lsg }}$ and bed slope $\mathrm{S}$. All parameters except $D_{\text {lsg }}$ pertain to the node farthest downstream. The overall pattern is identical to that seen in in Figure 7 for the runs with constant flow; bed slope $S$ increases, and surface geometric mean size $\mathrm{D}_{\mathrm{sg}}$ decreases, with increasing sediment feed rate $\mathrm{q}_{\mathrm{bTf}}$. Again, the progression from nearly static armor, to mobile armor, and finally to a condition for which the bed is nearly unarmored is readily evident.

Figure 20 shows the surface sand contents at the maximum flow (peak flow) fraction of sand content $\mathrm{F}_{\text {ssp }}$ and minimum flow (end flow) fraction of sand content $\mathrm{F}_{\text {sse }}$ in the surface layer (expressed in percentages) as functions of $\mathrm{q}_{\mathrm{bTf}}$. Again, the data are for the node farthest downstream and the last hydrograph of the run. Note that $F_{\text {sse }}$ and $F_{\text {ssp }}$ are essentially identical except at the highest two sediment feed rates. At these high feed rates the hydrograph boundary layer becomes somewhat diffuse, so that some effects of the upstream boundary conditions propagate weakly to the downstream end of the flume. The general pattern of Figure 20, according to which the fraction of sand in the surface layer increases with increasing sediment transport rate, closely parallels that seen in Figure 8 for the runs with constant flow.

Figure 21 shows comparisons of the equilibrium values of the following parameters for both the constant-flow runs and the hydrograph runs: a) surface geometric mean size $\mathrm{D}_{\mathrm{sg}}$ for constant flows and $D_{\text {sgp }}$ at the maximum (peak) flows for the hydrograph, b) fraction of sand in the surface layer $F_{s s}$ for constant flows and $F_{\text {ssp }}$ at the maximum (peak) flows for the hydrograph, and c) bed slope $S$ for both cases. Also shown for reference is the geometric mean size $D_{\operatorname{lgf}}$ of the feed sediment. It should be noted that the data for the constant-flow runs pertain to the node farthest upstream, whereas the data for the hydrograph runs pertain to the node farthest downstream. Having said this, in the case of mobile-bed equilibrium at constant discharge all parameters at the downstream node should take the same values as at the upstream node.

Figure 21 highlights the effect of the cycled hydrograph as opposed to constant flow corresponding to the average of the hydrograph continued for the same number of days per year. In all cases a cycled hydrograph leads to a bed with a lower slope and a finer surface layer than in the case of the corresponding constant flow. The difference between the two becomes progressively weaker as feed rate $\mathrm{q}_{\mathrm{bTf}}$ increases. The overall trends are, however, the same in both cases.

Figure 22 for the case of cycled hydrographs corresponds to Figure 9 for constant flows. It shows the downstream surface grain size distributions at mobile-bed equilibrium for all the numerical runs of Table 1 . Also shown is the grain size distribution of the feed. As 
in the case of Figure 9, the plot illustrates the progression from nearly static armor, to mobile armor and then to a state at which the bed is nearly unarmored as sediment feed rate $\mathrm{q}_{\mathrm{bTf}}$ increases.

Figures 23 and 24 pertain solely to the hydrograph runs. Figure 23 shows plots of surface geometric mean sizes at the maximum (peak) and minimum (end) flows $\mathrm{D}_{\mathrm{sgp}}$ and $\mathrm{D}_{\text {sge, }}$ respectively, as well as geometric mean sizes of the load at the maximum (peak) and minimum (end) flows $D_{\text {lgp }}$ and $D_{\text {lge }}$, respectively, versus sediment feed rate $q_{\mathrm{bTf}}$. Again, the values are for the node farthest downstream and the last hydrograph of the run. Also included is the geometric mean size $D_{\text {lgf }}$ of the feed sediment. Note that $D_{\text {sgp }}$ and $D_{\text {sge }}$ are virtually identical except at the highest feed rates, where (as is shown below) the hydrograph boundary layer becomes more diffuse. Even at the highest feed rates, however, they differ little. Note also, however, that $\mathrm{D}_{\operatorname{lgp}}$ is always coarser than $\mathrm{D}_{\text {lge. The }}$ difference is modest for the highest feed rate $\mathrm{q}_{\mathrm{bTf}}=1 \times 10^{-1} \mathrm{~m}^{2} / \mathrm{s}$, and reaches a maximum at a feed rate near $\mathrm{q}_{\mathrm{bTf}}=2 \times 10^{-4} \mathrm{~m}^{2} / \mathrm{s}$. The difference then declines with decreasing $\mathrm{q}_{\mathrm{bTf}}$. The decline in the difference between the bedload geometric mean sizes at the peak and end flows as q $q_{\mathrm{bTf}}$ declines below $2 \times 10^{-4} \mathrm{~m}^{2} / \mathrm{s}$ appears to be inherent in the formulation of Wilcock and Crowe (2003).

In the case of the lowest feed rate in Figure 23, the surface geometric mean size $D_{\text {sgp }}$ is seen to be slightly finer than that of the feed sediment. This likely reflects the fact that at a feed rate $q_{b T f}$ as low as $1 \times 10^{-6} \mathrm{~m}^{2} / \mathrm{s}$ even 120,000 years of run time is not quite sufficient to reach a (barely) mobile-bed equilibrium.

Figure 24 shows the fraction of sand in the surface and load at the maximum (peak) flow $F_{\text {ssp }}$ and $F_{\text {slp }}$, respectively, the corresponding fractions $F_{\text {sse }}$ and $F_{\text {sle }}$ at the minimum (end) flow, respectively, and the fraction of sand $\mathrm{F}_{\text {slf }}$ in the feed, all as functions of $\mathrm{q}_{\mathrm{bTf}}$. Again, the values correspond to the node farthest downstream and the last hydrograph of the run. Note that the sand fractions $\mathrm{F}_{\mathrm{ssp}}$ and $\mathrm{F}_{\text {sse }}$ in the surface layer are nearly identical to each other, whereas the sand fraction in the load at peak flow $F_{\text {slp }}$ tends to be markedly lower than the value $\mathrm{F}_{\text {sle }}$ at the end flow.

\section{A SIMPLER MODEL FOR THE HYDROGRAPH BOUNDARY LAYER}

The numerical model described above serves to identify the hydrograph boundary layer and the tradeoff associated with it, but it does not provide a particularly lucid explanation for the existence of the hydrograph boundary layer. In this section this explanation is pursued in the context of a simpler model using uniform sediment. The model is developed with the aid of singular perturbation techniques applied to boundary layer analysis (Nayfeh, 1993).

Consider the configuration of Figure 25, which differs from that of Figure 4 only in that the sediment fed in at the upstream is uniform with size D. The volume bedload transport rate for uniform sediment is denoted $\mathrm{as} \mathrm{q}_{\mathrm{b}}$, and the corresponding feed rate is denoted as

$\mathrm{q}_{\mathrm{bf}}$. Again, a cyclic hydrograph $\mathrm{q}_{\mathrm{w}}(\mathrm{t})$ is imposed, whereas the bedload feed rate $\mathrm{q}_{\mathrm{bf}}$ is held constant. Figure 26 for uniform sediment is an analog of Figure 10 for mixtures. It 
suggests that under the imposed conditions, bed elevation $\eta$ should fluctuate with discharge in a short hydrograph boundary layer downstream of the feed point. Farther downstream, however, the analogous tradeoff should result in bed elevation $\eta$ that is constant in time and a bedload transport rate that fluctuates over the hydrograph. Here a rescaling is used to establish the existence of this hydrograph boundary layer and quantify its characteristics.

Before pursuing the details of the analysis, it is useful to describe the results in advance without the use of equations. Any river reach with a given length and given characteristic bed material sediment supply has a characteristic time for morphodynamic evolution in response to imposed change. Now impose a cycled flow hydrograph but constant sediment feed rate onto this reach. If the time duration of the hydrograph is sufficiently long compared to the response time of the reach, the flow hydrograph imposes cyclic aggradation and degradation throughout the reach, even at mobile-bed equilibrium. If the time duration of the hydrograph is very short compared to the response time of the reach, however, the flow discharge changes so fast that the effect of any given flow discharge does not have enough time to propagate very far downstream before the discharge changes. As a result bed elevation fluctuations are restricted to a short hydrograph boundary layer near the feed point. Downstream of this hydrograph boundary layer bed elevation becomes invariant in time over the hydrograph, and instead the effect of the hydrograph is imprinted on the load, which varies cyclically in time.

In accordance with Figure 25, sediment is fed into a reach of length $\mathrm{L}$ at constant volume rate per unit width $\mathrm{q}_{\mathrm{bf}}$. Flow discharge per unit width $\mathrm{q}_{\mathrm{w}}$ varies, however, according to a cyclically repeated hydrograph:

$$
\mathrm{q}_{\mathrm{w}}=\mathrm{q}_{\mathrm{wo}}\left[1+\mathrm{f}_{\mathrm{w}}\left(\frac{\mathrm{t}}{\mathrm{T}_{\mathrm{h}}}\right)\right]
$$

where $\mathrm{q}_{\text {wo }}$ denotes a characteristic discharge of a base state (without fluctuations) and $\mathrm{T}_{\mathrm{h}}$ denotes the duration of the hydrograph. Eventually a final equilibrium state is obtained. What are its characteristics?

The Exner equation of sediment continuity for uniform sediment is written as

$$
\left(1-\lambda_{\mathrm{p}}\right) \frac{\partial \eta}{\partial \mathrm{t}}=-\frac{\partial \mathrm{q}_{\mathrm{b}}}{\partial \mathrm{x}}
$$

A very simple sediment transport equation is used here for illustrative purposes;

$$
\mathrm{q}=\alpha_{\mathrm{b}} \mathrm{q}_{\mathrm{w}} \mathrm{S}
$$

where $\alpha_{\mathrm{b}}$ is a constant. Such an equation can be obtained from a relation of the type of Meyer-Peter and Müller (1948) at sufficiently high Shields number, the assumption of a constant coefficient of bed resistance $\mathrm{C}_{\mathrm{f}}$, where

$$
\mathrm{C}_{\mathrm{f}}^{-1 / 2}=\frac{\mathrm{U}}{\mathrm{u}_{*}}=\frac{\mathrm{q}_{\mathrm{w}}}{\mathrm{Hu}_{*}}
$$

and the normal flow assumption of (14), in which case

$$
\alpha_{b}=8 \frac{C_{f}^{1 / 2}}{R}
$$


It should be pointed out, however, that the general nature of the results obtained here are not dependent on the precise nature of the bedload transport equation.

The boundary conditions on (24) are

$$
\left.\mathrm{q}_{\mathrm{b}}\right|_{\mathrm{x}=0}=\mathrm{q}_{\mathrm{bf}},\left.\quad \eta\right|_{\mathrm{x}=\mathrm{L}}=0
$$

In the analysis of this section the hydrograph described by (23) is repeated cyclically with no intermittency, i.e. no periods of low flow. That is, time is compressed to exclude periods of morphodynamically inactive low flow.

The base equilibrium state associated with constant discharge $\mathrm{q}_{\text {wo }}$ and sediment feed rate $\mathrm{q}_{\mathrm{bf}}$ is given as

$$
\mathrm{S}_{\mathrm{o}}=\frac{1}{\alpha_{\mathrm{b}}} \frac{\mathrm{q}_{\mathrm{bf}}}{\mathrm{q}_{\mathrm{w}}}, \eta_{\mathrm{o}}=\mathrm{S}_{\mathrm{o}} \mathrm{L}\left(1-\frac{\mathrm{x}}{\mathrm{L}}\right)
$$

Now the solution of (24) subject to (28) is written as

$$
\eta=\eta_{\mathrm{o}}(\mathrm{x})+\eta_{\mathrm{d}}(\mathrm{x})
$$

where $\eta_{\mathrm{d}}$ denotes a deviatoric bed elevation around the base equilibrium state. Substituting (30) into (18) and using the result and (29a) to reduce (25), it is found that

$$
\begin{aligned}
& \mathrm{q}_{\mathrm{b}}=\mathrm{q}_{\mathrm{bf}}\left(1+\mathrm{f}_{\mathrm{w}}\right)\left(1-\frac{1}{\mathrm{~S}_{\mathrm{o}}} \frac{\partial \eta_{\mathrm{d}}}{\partial \mathrm{x}}\right) \\
& \mathrm{S}=\mathrm{S}_{\mathrm{o}}\left(1-\frac{1}{\mathrm{~S}_{\mathrm{o}}} \frac{\partial \eta_{\mathrm{d}}}{\partial \mathrm{x}}\right)
\end{aligned}
$$

Equation (24) reduces with (29a) to

$$
\left(1-\lambda_{\mathrm{p}}\right) \frac{\partial \eta_{\mathrm{d}}}{\partial \mathrm{t}}=\frac{\mathrm{q}_{\mathrm{bf}}}{\mathrm{S}_{\mathrm{o}}}\left(1+\mathrm{f}_{\mathrm{w}}\right) \frac{\partial^{2} \eta_{\mathrm{d}}}{\partial \mathrm{x}^{2}}
$$

The boundary conditions $(28 a, b)$ on (33) reduce to

$$
\left.\frac{\partial \eta_{d}}{\partial x}\right|_{x=0}=S_{o} \frac{f_{w}}{1+f_{w}} \quad,\left.\quad \eta_{d}\right|_{x=L}=0
$$

The problem is made dimensionless as follows:

$$
\begin{aligned}
& \mathrm{x}=\mathrm{Lx}_{\mathrm{n}}, \quad \eta_{\mathrm{d}}=\mathrm{S}_{\mathrm{o}} \mathrm{L} \eta_{\mathrm{n}}, \quad \mathrm{t}=\left(1-\lambda_{\mathrm{p}}\right) \frac{\mathrm{S}_{\mathrm{o}} \mathrm{L}^{2}}{\mathrm{q}_{\mathrm{bf}}} \mathrm{t}_{\mathrm{n}} \\
& \mathrm{S}=\mathrm{S}_{\mathrm{o}} \mathrm{S}_{\mathrm{n}} \quad \mathrm{q}_{\mathrm{b}}=\mathrm{q}_{\mathrm{bf}} \mathrm{q}_{\mathrm{n}}
\end{aligned}
$$

Note that according to the above transformations, dimensionless distance $x_{n}$ varies from 0 to 1 and dimensionless slope and bedload transport rate fluctuate around unity. This rescaling allows the determination of a dimensionless parameter that must be small in order for a hydrograph boundary layer to be manifested.

The parameters $x_{n}$ and $\eta_{n}$ are hereby termed "outer variables," in the sense that they are the relevant parameters for describing channel morphodynamics outside the hydrograph boundary layer. That is, downstream distance $\mathrm{x}$ is normalized against total reach length $\mathrm{L}$ 
and deviatoric bed elevation $\eta_{\mathrm{d}}$ is normalized against the elevation difference between the upstream and downstream end of the reach in the absence of elevations. Note also that $t$ is normalized against a characteristic time for morphodynamic response $T_{m}$ of the entire channel reach (with length $\mathrm{L}$ ) by aggradation or degradation, where

$$
\mathrm{T}_{\mathrm{m}}=\left(1-\lambda_{\mathrm{p}}\right) \frac{\mathrm{S}_{\mathrm{o}} \mathrm{L}^{2}}{\mathrm{q}_{\mathrm{bf}}}
$$

so that (35c) can be recast in the form

$$
\mathrm{t}=\mathrm{T}_{\mathrm{m}} \mathrm{t}_{\mathrm{n}}
$$

That (35f) does indeed correspond to a characteristic morphologic response time can be seen as follows. Consider a reach of zero slope and length L. If sediment were fed into this reach at rate $q_{b f}$ to form wedge-shaped deposit with slope $S_{o}$, vanishing elevation at the downstream end and deposit porosity $\lambda_{\mathrm{p}}$, and no sediment outflow were allowed, the amount of time required to fill with wedge would be equal to $\mathrm{T}_{\mathrm{m}} / 2$.

Substituting (35a-e) into (33), (34a,b), (31) and (32), the following dimensionless relations are obtained;

$$
\begin{aligned}
& \frac{\partial \eta_{\mathrm{n}}}{\partial \mathrm{t}_{\mathrm{n}}}=\left(1+\mathrm{f}_{\mathrm{w}}\right) \frac{\partial^{2} \eta_{\mathrm{n}}}{\partial \mathrm{x}_{\mathrm{n}}^{2}} \\
& \left.\frac{\partial \eta_{\mathrm{n}}}{\partial \mathrm{x}_{\mathrm{n}}}\right|_{\mathrm{x}_{\mathrm{n}}=0}=\frac{\mathrm{f}_{\mathrm{w}}}{1+\mathrm{f}_{\mathrm{w}}},\left.\quad \eta_{\mathrm{n}}\right|_{\mathrm{x}_{\mathrm{n}}=1}=0 \\
& \mathrm{~S}_{\mathrm{n}}=1-\frac{\partial \eta_{\mathrm{n}}}{\partial \mathrm{x}_{\mathrm{n}}}, \quad \mathrm{q}_{\mathrm{n}}=\left(1+\mathrm{f}_{\mathrm{w}}\right)\left(1-\frac{\partial \eta_{\mathrm{n}}}{\partial \mathrm{x}_{\mathrm{n}}}\right)
\end{aligned}
$$

Recalling that $f_{w}$ is a function of $t / T_{h}$, where $T_{h}$ denotes the length (period) of the hydrograph, it follows from (35c) that

$$
\mathrm{f}_{\mathrm{w}}=\mathrm{f}_{\mathrm{w}}\left(\frac{\mathrm{t}_{\mathrm{n}}}{\varepsilon}\right)
$$

where

$$
\varepsilon=\frac{\mathrm{q}_{\mathrm{bf}} \mathrm{T}_{\mathrm{h}}}{\left(1-\lambda_{\mathrm{p}}\right) \mathrm{S}_{\mathrm{o}} \mathrm{L}^{2}}=\frac{\mathrm{T}_{\mathrm{h}}}{\mathrm{T}_{\mathrm{m}}}
$$

The rest of the analysis is based on the assumption that

$$
\varepsilon=\frac{\mathrm{T}_{\mathrm{h}}}{\mathrm{T}_{\mathrm{m}}}<<1
$$

This assumption implies that the duration of a single hydrograph is very short compared to the characteristic time needed to effect morphodynamic change over the entire channel. It will be shown that a well-defined hydrograph boundary layer appears under the constraint of (40), or more precisely when $\varepsilon^{1 / 2}<<1$.

The equations are further transformed from the time variable $t_{n}$ to a time variable $\hat{t}$ defined so that $\hat{t}$ varies by a factor of unity over a single hydrograph: 


$$
\hat{\mathrm{t}}=\frac{\mathrm{t}_{\mathrm{n}}}{\varepsilon}=\frac{\mathrm{t}}{\mathrm{T}_{\mathrm{h}}}
$$

Substituting (41) into (36a) and reducing,

$$
\frac{\partial \eta_{\mathrm{n}}}{\partial \hat{\mathrm{t}}}=\varepsilon\left(1+\mathrm{f}_{\mathrm{w}}\right) \frac{\partial^{2} \eta_{\mathrm{n}}}{\partial \mathrm{x}_{\mathrm{n}}^{2}}
$$

Now in general (42) combined with (40) implies that bed elevation is changing only slowly in time. However, when the final (cyclic) equilibrium is reached, (42) combined with (36c) gives in the limit as $\varepsilon \rightarrow 0$ the result

$$
\eta_{\mathrm{n}}=0
$$

That is, the deviatoric bed elevation (and thus deviatoric bed slope) can be set equal to zero at the final cyclic equilibrium, and the dimensioned bed profile is given by (29b) of the base state. At this same cyclic equilibrium the (dimensioned) sediment transport rate is given from (31a) and (37b) in the limit as $\varepsilon \rightarrow 0$ as

$$
\mathrm{q}_{\mathrm{b}}=\mathrm{q}_{\mathrm{bf}}\left(1+\mathrm{f}_{\mathrm{w}}\right)
$$

That is, deviatoric bed elevation and slope vanish, whereas the sediment transport rate follows the hydrograph.

The above solution is precisely that hypothesized in Figure 26 to prevail everywhere except in a hydrograph boundary layer near the sediment feed point; bed elevation and bed slope do not vary over the hydrograph, and the bedload transport rate tracks the hydrograph in accordance with (44).

Now the above solution is incapable of satisfying (36b) at $x_{n}=0$. This does not mean that the solution is wrong, but rather that it breaks down in the vicinity of $x_{n}=0$. More specifically, the satisfaction of (36b) requires the existence of a "thin" boundary layer near $x_{n}=0$ where the solution differs form the one given above. To this end, the transformations

$$
\eta_{\mathrm{n}}=\varepsilon^{1 / 2} \tilde{\eta} \quad, \quad x_{\mathrm{n}}=\varepsilon^{1 / 2} \tilde{\mathrm{x}}
$$

are introduced into (36a) and (36b), resulting in the relations

$$
\frac{\partial \tilde{\eta}}{\partial \hat{\mathrm{t}}}=\left(1+\mathrm{f}_{\mathrm{w}}\right) \frac{\partial^{2} \tilde{\eta}}{\partial \tilde{\mathrm{x}}^{2}} \quad,\left.\quad \frac{\partial \tilde{\eta}}{\partial \tilde{\mathrm{x}}}\right|_{\tilde{\mathrm{x}}=0}=\frac{\mathrm{f}_{\mathrm{w}}}{1+\mathrm{f}_{\mathrm{w}}}
$$

The variables with the tildes in $(45 a, b)$ are referred as "inner variables," as they scale the problem within the hydrograph boundary layer.

One more boundary condition on the above set is obtained by limit matching to the outer solution;

$$
\left.\tilde{\eta}\right|_{\tilde{x}=\infty}=0
$$

In practical terms this is replaced with

$$
\left.\tilde{\eta}\right|_{\tilde{x}=\tilde{L}}=0
$$

where $\tilde{\mathrm{L}}$ might be equal to 5 or 10 . (The precise value is irrelevant as long as it is sufficiently large compared to unity; see Nayfeh, 1993). Note that the dimensioned 
distance $\mathrm{x}_{\tilde{\mathrm{L}}}$ from the feed point corresponding to any value $\tilde{\mathrm{L}}$ is given from (45b) and (35a) as $\varepsilon^{1 / 2} \tilde{L} L$, so that if $\varepsilon^{1 / 2}$ is sufficiently small $x_{\tilde{L}}$ is only a small fraction of reach length $\mathrm{L}$.

Note that in the above formulation $\mathrm{f}_{\mathrm{w}}(\hat{\mathrm{t}})$ is periodic with period 1 . All that remains here is for (46a) to be solved subject to (46b,d) at cyclic equilibrium. The problem is linear; here a numerical formulation is used. In a numerical formulation, it is necessary to "spin up" to the mobile-bed equilibrium solution; an appropriate initial condition is

$$
\left.\tilde{\eta}\right|_{\hat{t}=0}=0
$$

Dimensionless load takes the following form in inner variables;

$$
\mathrm{q}_{\mathrm{n}}=\left(1+\mathrm{f}_{\mathrm{w}}\right)\left(1-\frac{\partial \tilde{\eta}}{\partial \tilde{\mathrm{x}}}\right)
$$

Calculations were performed using a simple sinusoidal specification for $\mathrm{f}_{\mathrm{w}}$ :

$$
\mathrm{f}_{\mathrm{w}}(\hat{\mathrm{t}})=\mathrm{a}_{\mathrm{h}} \sin (2 \pi \hat{\mathrm{t}})
$$

where $a_{h}$ is a dimensionless amplitude of discharge fluctuation. That is, (49) specifies the fluctuating part of the cyclically repeated hydrograph. Thus (46a) was solved numerically subject to the boundary conditions (46b) and (46d), the initial condition (47), the specification

$$
\tilde{\mathrm{L}}=10
$$

and the range $0.05<a_{h}<0.6$. In performing the calculations the domain $0 \leq \tilde{\mathrm{x}} \leq \tilde{\mathrm{L}}$ was divided into 80 intervals and the hydrograph was discretized into 32 time steps. The calculation was continued until a final (fluctuating) equilibrium state was obtained.

Figure 27 shows a plot of dimensionless deviatoric bed elevation profiles in terms of the inner variable form $\tilde{\eta}$ versus dimensionless distance from the feed point, again in terms of the inner variable form $\tilde{\mathrm{x}}$ for all 32 steps of the last hydrograph of the numerical run, by which time a mobile-bed equilibrium had been achieved. Deviatoric bed elevation is seen to fluctuate strongly in the range $\tilde{\mathrm{x}}<2$, but for larger values of $\tilde{\mathrm{x}}$ the fluctuations disappear. The zone where $\tilde{\eta}$ varies strongly over the hydrograph corresponds to the hydrograph boundary layer.

Figure 28 shows a plot of dimensionless bedload transport rate $\mathrm{q}_{\mathrm{n}}$ versus $\tilde{\mathrm{x}}$, again for all 32 steps of the final hydrograph. Note that $\mathrm{q}_{\mathrm{n}}$ is precisely equal to 1 (bedload transport rate $=$ feed rate) at $\tilde{x}=0$, but downstream of $\tilde{x}=2$ it is seen that $q_{n}$ strongly tracks the hydrograph, precisely as postulated in Figure 25.

Dimensionless boundary layer thickness $\tilde{\mathrm{x}}_{\delta}$ can be defined as follows. Let $\tilde{\mathrm{x}}_{\delta}$ denote the smallest value of $\tilde{\mathrm{x}}$ such that the following condition is satisfied;

$$
\frac{\max \left|\tilde{\eta}\left(\tilde{x}_{\delta}, \hat{t}\right)\right|}{\max |\tilde{\eta}(0, \hat{\mathrm{t}})|} \leq \chi_{\text {tol }}
$$


where $\chi_{\text {tol }}$ is a dimensionless tolerance that must take a value sufficiently small compared to unity so as to allow the neglect of fluctuations in $\tilde{\eta}$ for $\tilde{x}>\widetilde{x}_{\delta}$. Here $\chi_{\text {tol }}$ is set equal to 0.01 . Figure 29 shows a plot of $\tilde{x}_{\delta}$ versus $a_{h}$ for the calculations performed here. It is seen that $\tilde{\mathrm{x}}_{\delta}$ does not vary strongly in $\mathrm{a}_{\mathrm{h}}$ over the range, $0.05 \leq \mathrm{a}_{\mathrm{h}} \leq 0.6$, ranging from about 2.5 at the lower value of $a_{h}$ to about 2.2 at the higher value. It should be noted that a tolerance $\chi_{\text {tol }}$ of 0.01 quite small, resulting in an estimate of boundary layer thickness that is toward the high side.

It is now possible to characterize the hydrograph boundary layer thickness in dimensioned terms. Let $\mathrm{x}=\delta$ denote the distance from the feed point $(\mathrm{x}=0)$ to a point downstream of which elevation fluctuations can be neglected, i.e. the point where the equality in (51) is satisfied. This value of $\delta$ denotes the thickness, or length of the hydrograph boundary layer. Between (35a) and (45b) it is found that

$$
\frac{\delta}{\mathrm{L}}=\varepsilon^{1 / 2} \tilde{\mathrm{x}}_{\delta}
$$

Since $\tilde{\mathrm{x}}_{\delta}$ is in the range $2.1 \sim 2.5$ for the calculations performed here, it follows that the hydrograph boundary layer length is short compared to the reach length $L$ as long as

$$
\varepsilon^{1 / 2}<<1
$$

Reducing (52) with (39), it is further found that

$$
\frac{\delta}{\mathrm{L}}=\left[\frac{\mathrm{q}_{\mathrm{bf}} \mathrm{T}_{\mathrm{h}}}{\left(1-\lambda_{\mathrm{p}}\right) \mathrm{S}_{\mathrm{o}} \mathrm{L}^{2}}\right]^{1 / 2} \tilde{\mathrm{x}}_{\delta}=\left[\frac{\mathrm{T}_{\mathrm{h}}}{\mathrm{T}_{\mathrm{m}}}\right]^{1 / 2} \tilde{\mathrm{x}}_{\delta}
$$

The above relation justifies the verbal description given at the beginning of this section. That is, as long as hydrograph duration $T_{h}$ is sufficiently short compared to the characteristic time of morphologic response $T_{m}$, bed elevation fluctuations are restricted to a short hydrograph boundary layer downstream of the feed point. Downstream of this bed elevation becomes invariant, and instead the bedload transport rate fluctuates cyclically with the hydrograph.

The above equation indicates that the ratio of the hydrograph boundary layer length to the reach length increases with increasing bedload transport rate $\mathrm{q}_{\mathrm{bo}}$ (= feed rate). This is why at least some weak influence of the upstream conditions are felt at the downstream end of the runs with the highest bedload feed rates in Table 1.

Now (54) does not apply precisely to the runs of Table 1, because its derivation uses a highly simplified bedload transport relation that does not treat mixtures. This notwithstanding, the result of a more detailed analysis is likely to have a form similar to (54). With this in mind, (54) is applied as a crude approximation to estimate the ratio $\delta / \mathrm{L}$ as a function of volume bedload feed rate per unit width $\mathrm{q}_{\mathrm{bTf}}$ for the numerical runs of Table 1. In performing the calculation, $\mathrm{T}_{\mathrm{h}}$ is set equal to 4.5 days and $\lambda_{\mathrm{p}}$ is set equal to 0.4 , as was done in the case of the numerical runs of Table 1 . In addition, $\tilde{\mathrm{x}}_{\delta}$ is loosely estimated as 2.5, and the value used for $\mathrm{S}_{\mathrm{o}}$ in (54) is the final equilibrium bed slope (downstream of the hydrograph boundary layer) for each run, as listed in Table 1 
Figure 30 shows the estimate of $\delta / L$ versus $q_{b T f}$ obtained in this way for the experiments of Table 1. The plot suggests that the hydrograph boundary layer should be very thin indeed near the lowest feed rates, but should no longer be short compared to the reach length (and indeed, occupy on the order of 40 percent of the reach length) at the highest feed rate. This is in accord with the results presented in regard to the numerical runs of Table 1, according to which the hydrograph boundary layer can be expected to become thicker and more diffuse as bedload feed rate increases.

The above analysis can be generalized in a straightforward way for a) more realistic bedload transport equations for uniform sediment and b) bedload transport equations for mixtures. Such an analysis would reveal two characteristic morphodynamics time scales for the case of mixtures, i.e. the one expressed in (35f) which characterizes the response time for bed aggradation or degradation, and a shorter time scale characterizing the response time for the bed surface layer to adjust to the flow regime. The time scale of the hydrograph must in principle be short compared to the smallest of these time scales in order for a distinct hydrograph boundary layer to be manifested. The two time scales reduce to a single scale for the case of uniform sediment considered in this section. The simplicity of this case allows a relatively clear explanation of the phemonenon of the hydrograph boundary layer.

A more complete version of the above analysis, along with a comparison with experimental data can be found in Wong and Parker (in press).

\section{CAVEATS}

A careful perusal of Figure 19 reveals that the geometric mean size of the bedload $D_{\text {lg }}$ averaged over the hydrograph at mobile-bed equilibrium is quite close to the geometric mean size of the bedload feed $D_{\text {lgf }}$, but not identical to it. The two should in fact be identical. The discrepancy is partly associated with numerical issues, particularly in the case of Run $11 \mathrm{H}$, for which the feed rate $\mathrm{q}_{\mathrm{bTf}}$ is so low that even 120,000 year of run time is not quite sufficient to reach mobile-bed equilibrium.

There is, however, another reason for the modest discrepancy. Equation (9) was not precisely implemented in the calculations reported here. In a precise implementation, new substrate with a vertically varying grain size distribution would be stored as the bed aggrades, and this substrate would be mined as the bed degrades subsequently. Such an implementation, while not difficult in principle, imposes large constraints on computational memory, as the vertical structure of the substrate must be stored dynamically. Here the calculations were simplified by assuming that the substrate size distribution is always equal to the initial value. This simplification introduces a modest but discernible error in the calculations in the approach to mobile-bed equilibrium.

In several places in the description the bed is characterized as being "unarmored" or "nearly unarmored" for sufficiently high gravel supply. A more precise description is that the surface size distribution approaches that of the load at sufficiently high transport 
rates. This translates into the elimination of the armor layer only when the substrate has a similar size distribution, or is coarser than the load. This condition appears, however to prevail in most cases of interest (e.g. Lisle, 1995).

The conclusions presented here, and more precisely the conclusion that the surface layer of a gravel-bed river tends to evolve so that its grain size distribution becomes independent of flow, is based on a 1D numerical model in which all form drag and all 2D effects such as bars and local sorting have been neglected. In addition, the hydrograph is deterministic and cyclically repeated rather than stochastic. Including such factors might change the results, which thus must remain somewhat tentative.

The present results apply to mobile-bed equilibrium. They may apply to field gravel-bed streams that are a) subject to hydrologic regime that does not deviate too much from statistical invariance and b) are otherwise not too far from grade. They are unlikely to apply to streams that are measurably out of equilibrium.

\section{CONCLUSIONS}

A 1D numerical model is presented for the morphodynamic evolution to mobile-bed equilibrium of a reach of a gravel-bed river transporting gravel and sand as bedload. A cycled hydrograph is imposed on the reach, but the upstream sediment feed rate and size distribution are held constant. The following results are obtained at mobile-bed equilibrium over a broad range of conditions.

- Just downstream of the feed point the bed elevation, bed slope and bed surface size distribution fluctuate cyclically over the hydrograph, as the bed responds to the imbalance between transport capacity and supply.

- This behavior is, however, restricted to a short reach, or hydrograph boundary layer downstream of the feed point.

- Downstream of the hydrograph boundary layer, a tradeoff in fluctuations between bed and bedload takes place. That is, the bed evolves to a bed elevation, bed slope and bed surface size distribution that become invariant to the hydrograph. The response to the hydrograph is instead expressed in terms of a bedload transport rate and a bedload size distribution that fluctuate cyclically with the hydrograph. This behavior prevails over the great majority of the reach in question.

- The hydrograph boundary layer is shortest and sharpest when the duration of the hydrograph is very short compared to the characteristic morphodynamic response time of the reach. This is because the flow changes so rapidly in time that the effect of constant bedload magnitude and size distribution imposed upstream is not able to propagate far downstream.

- As the duration of the hydrograph becomes longer compared to the characteristic morphodynamic response time of the reach, the hydrograph boundary layer becomes thick compared to the reach length, and more diffuse as well. Such conditions are approached as the bedload feed rate becomes sufficiently high.

- A hydrograph boundary layer could be identified in all cases over the range of bedload feed rates studied here. Some weak effect of the upstream boundary 
condition was exerted on the bed surface size distribution at the downstream end, however, in the cases of the highest bedload feed rates.

The main conclusion of this paper may have an important practical application. Let us assume, at least tentatively, that real gravel-bed rivers, with all their complications which are not included in the present numerical model, nevertheless behave similarly to that described above. It then follows that the surface size distribution present during floods (which is not easily sampled) may differ little from that prevailing at low flow (which is easily sampled). If this were to be true, it would greatly simplify the application of surface-based gravel transport relations to rivers at flood flows.

\section{ACKNOWLEDGEMENTS}

This work was supported by the National Science Foundation via Agreement Number EAR-0207274. Additional support was derived from the STC program of the National Science Foundation via the National Center for Earth-surface Dynamics under Agreement Number EAR-0120914. This paper represents a contribution of the research of the National Center for Earth-surface Dynamics in the area of channel dynamics. The following graduate students in a class on morphodynamics offered by the first author in 2004 presented as part of a final examination preliminary versions of some of the results presented here: P. Chatanantavet, R. Hauck, W. Kim, J. W. Lauer, N. Strong, M. Tal and M. Wong. The first author thanks M. Wong for many interesting and helpful discussions.

\section{REFERENCES}

Andrews, E. D. and Erman, D. C. 1986. Persistence in the size distribution of surficial bed material during an extreme snowmelt flood. Water Resources Research 22, 191-197.

Hoey, T. B., and R. I. Ferguson. 1994. Numerical simulation of downstream fining by selective transport in gravel bed rivers: Model development and illustration. Water Resources Research 30, 2251-2260.

Hollingshead, A. B. 1971. Sediment transport measurements in a gravel river. Journal of Hydraulic Engineering 97(11), 1817-1834.

Hunziker, R. and Jaeggi, M. N. R. 2002. Grain sorting processes. Journal of Hydraulic Engineering 128(12), 1060-1068.

Larson, G. 1984. In Search of the Far Side. Andrews McMeel Publishing, Kansas City, USA, $104 \mathrm{p}$.

Lisle, T. E. 1995. Particle size variations between bed load and bed material in natural gravel bed channels. Water Resources Research 31(4), 1107 - 1118.

Meyer-Peter, E. and Müller, R. 1948. Formulas for Bed-Load Transport. Proceedings, 2nd Congress, International Association of Hydraulic Research, Stockholm, 39-64.

Milhous, R. T. 1973. Sediment Transport in a Gravel-bottomed Stream. Ph.D. thesis, Oreg. State Univ., Corvallis.

Nayfeh. A. H. 1993. Introduction to Perturbation Techniques. John Wiley, ISBN: 0471-31013-1, $536 \mathrm{p}$. 
Parker, G., 1990. Surface-based bedload transport relation for gravel rivers. Journal of Hydraulic Research 28(4), 417-436.

Parker., G., 2004. 1D Sediment Transport Morphodynamics with Applications to Rivers and Turbidity Currents, e-book downloadable at http://www.cee.umn.edu/ parker/morphodynamics_e-book.htm.

Parker, G., Dhamotharan, S. and Stefan, H. 1982. Model experiments on mobile, paved gravel bed streams. Water Resources Research 18(5), 1395-1408.

Parker, G. and Klingeman, P. C. 1982. On why gravel bed streams are paved. Water Resources Research 18(5), 1409-1423.

Parker, G. and Sutherland, A. J. 1990. Fluvial armor. Journal of Hydraulic Research 28(5), 529-544.

Powell, D. M., Reid, I. and Laronne, J. B. 2001. Evolution of bedload grain-size distribution with increasing flow strength and the effect of flow duration on the caliber of bedload sediment yield in ephemeral gravel-bed rivers. Water Resources Research 37(5), 1463-1474.

Toro-Escobar, C. M., Parker G. and Paola, C. 1996. Transfer function for the deposition of poorly sorted gravel in response to streambed aggradation. Journal of Hydraulic Research, 34(1), 35-53.

Wilcock, P. R., Kenworthy, S. T. and Crowe, J. C. 2001. Experimental study of the transport of mixed sand and gravel. Water Resources Research 37(12), 3349-3358.

Wilcock, P. R. and Crowe, J. C. 2003. Surface-based transport model for mixed-size sediment. Journal of Hydraulic Engineering 129(2), 120-128.

Wilcock, P. R. and DeTemple, B. T. 2005. Persistence of armor layers in gravel-bedded streams. Geophysical Research Letters, 32, L08402, doi:10.1029/2004GL021772, 4 p.

Wong, M. and Parker, G. in press One-dimensional modeling of morphodynamic bed evolution of a gravel-bed river subject to a cycled hydrograph. Journal of Geophysical Research Earth Surface, preprint downloadable at: http://cee.uiuc.edu/people/parkerg/preprints.htm

\section{NOTATION}

$\mathrm{a}_{\mathrm{h}}$

$\mathrm{a}_{\mathrm{u}}$

$\mathrm{B}$

$\mathrm{C}_{\mathrm{f}}$

D

$\mathrm{D}_{\mathrm{i}}$

$D_{\lg }$

Dlge

$\mathrm{D}_{\text {lgf }}$

$\mathrm{D}_{\operatorname{lgp}}$

$\mathrm{D}_{150 \mathrm{f}}$

$\mathrm{D}_{\mathrm{sg}}$
Dimensionless amplitude of flow discharge fluctuation for the sinusoidal hydrograph of the analysis for uniform sediment

upwinding coefficient used in calculating spatial derivatives of parameters involving bedload transport

channel width

bed friction coefficient defined by (26)

sediment size

characteristic sediment size of the ith grain size range

geometric mean size of bedload

geometric mean size of bedload at end flow of hydrograph

geometric mean size of feed sediment

geometric mean size of bedload at peak flow of hydrograph

median size of the feed sediment

geometric mean size of sediment in surface layer 


\begin{tabular}{|c|c|}
\hline $\mathrm{D}_{\mathrm{sga}}$ & $\begin{array}{l}\text { geometric mean size of sediment in surface layer averaged over } \\
\text { hydrograph }\end{array}$ \\
\hline$D_{\text {sge }}$ & $\begin{array}{l}\text { geometric mean size of sediment in surface layer at end flow of } \\
\text { hydrograph }\end{array}$ \\
\hline $\mathrm{D}_{\text {sgp }}$ & $\begin{array}{l}\text { geometric mean size of sediment in surface layer at peak flow of } \\
\text { hydrograph }\end{array}$ \\
\hline$D_{s 90}$ & surface size such that 90 percent of a sample is finer \\
\hline $\mathrm{F}_{\mathrm{sl}}$ & fraction of sand in bedload \\
\hline $\mathrm{F}_{\text {sle }}$ & fraction of sand in bedload at end flow of hydrograph \\
\hline $\mathrm{F}_{\text {slf }}$ & fraction of sand in feed sediment \\
\hline $\mathrm{F}_{\text {slp }}$ & fraction of sand in bedload at peak flow of hydrograph \\
\hline $\mathrm{F}_{\mathrm{sS}}$ & fraction of sand in surface layer \\
\hline $\mathrm{F}_{\text {sse }}$ & fraction of sand in surface layer at end flow of hydrograph \\
\hline $\mathrm{F}_{\mathrm{ssp}}$ & fraction of sand in surface layer at peak flow of hydrograph \\
\hline$f_{h}$ & $\begin{array}{l}\text { functional notation for the fluctuating part of the hydrograph used in the } \\
\text { analysis for uniform sediment; see (23) }\end{array}$ \\
\hline $\mathrm{f}_{\mathrm{i}}$ & volume fraction of substrate material in the ith grain size range \\
\hline $\mathrm{f}_{\mathrm{Ii}}$ & $\begin{array}{l}\text { volume fraction of material in the ith grain size range exchanged across } \\
\text { the surface-substrate interface as the bed aggrades or degrades }\end{array}$ \\
\hline$F_{i}$ & volume fraction of surface material in the ith grain size range \\
\hline g & gravitational acceleration \\
\hline $\mathrm{H}$ & flow depth \\
\hline $\mathrm{k}$ & index for nodes in spatial discretization \\
\hline $\mathrm{k}_{\mathrm{s}}$ & bed roughness height for resistance calculations \\
\hline $\mathrm{L}_{\sim}$ & reach length \\
\hline$\tilde{\mathrm{L}}$ & $\begin{array}{l}\text { appropriately large value of } \tilde{\mathrm{x}} \text { chosen to be well outside the hydrograph } \\
\text { boundary layer (but still only a short distance downstream of the } \\
\text { feed point compared to reach length } \mathrm{L} \text { ) }\end{array}$ \\
\hline $\mathrm{L}_{\mathrm{a}}$ & thickness of the active (surface) layer \\
\hline M & number of spatial intervals in discretization \\
\hline$n_{a}$ & $\begin{array}{l}\text { coefficient relating the thickness of the active (surface) layer } L_{a} \text { to surface } \\
\text { size } D_{s 90}\end{array}$ \\
\hline$n_{k}$ & coefficient relating the roughness height $k_{s}$ of the flow to surface size $D_{s 90}$ \\
\hline$n_{\text {step }}$ & $\begin{array}{l}\text { number of time steps (each with length } \Delta \mathrm{t}_{\mathrm{f}} \text { ) that a single step of the } \\
\text { hydrograph is divided into }\end{array}$ \\
\hline Pbi & fraction of bedload material in the ith grain size range \\
\hline $\mathrm{q}_{\mathrm{b}}$ & volume transport rate of bedload per unit width for uniform sediment \\
\hline $\mathrm{q}_{\mathrm{bf}}$ & feed value of $\mathrm{q}_{\mathrm{b}}$ \\
\hline$q_{b f i}$ & volume feed rate of bedload per unit width in the ith grain size range \\
\hline $\mathrm{q}_{\mathrm{bi}}$ & volume transport rate of bedload per unit width in the ith grain size range \\
\hline $\mathrm{q}_{\mathrm{bT}}$ & $\begin{array}{l}\text { volume transport rate of bedload per unit width summed over all grain } \\
\text { sizes }\end{array}$ \\
\hline $\mathrm{q}_{\mathrm{bTf}}$ & volume feed rate of bedload per unit width summed over all grain sizes \\
\hline & dimensionless bedload transport rate defined by (35e) \\
\hline $\mathrm{Q}_{\mathrm{w}}$ & water discharge \\
\hline $\mathrm{q}_{\mathrm{w}}$ & water discharge per unit width \\
\hline
\end{tabular}




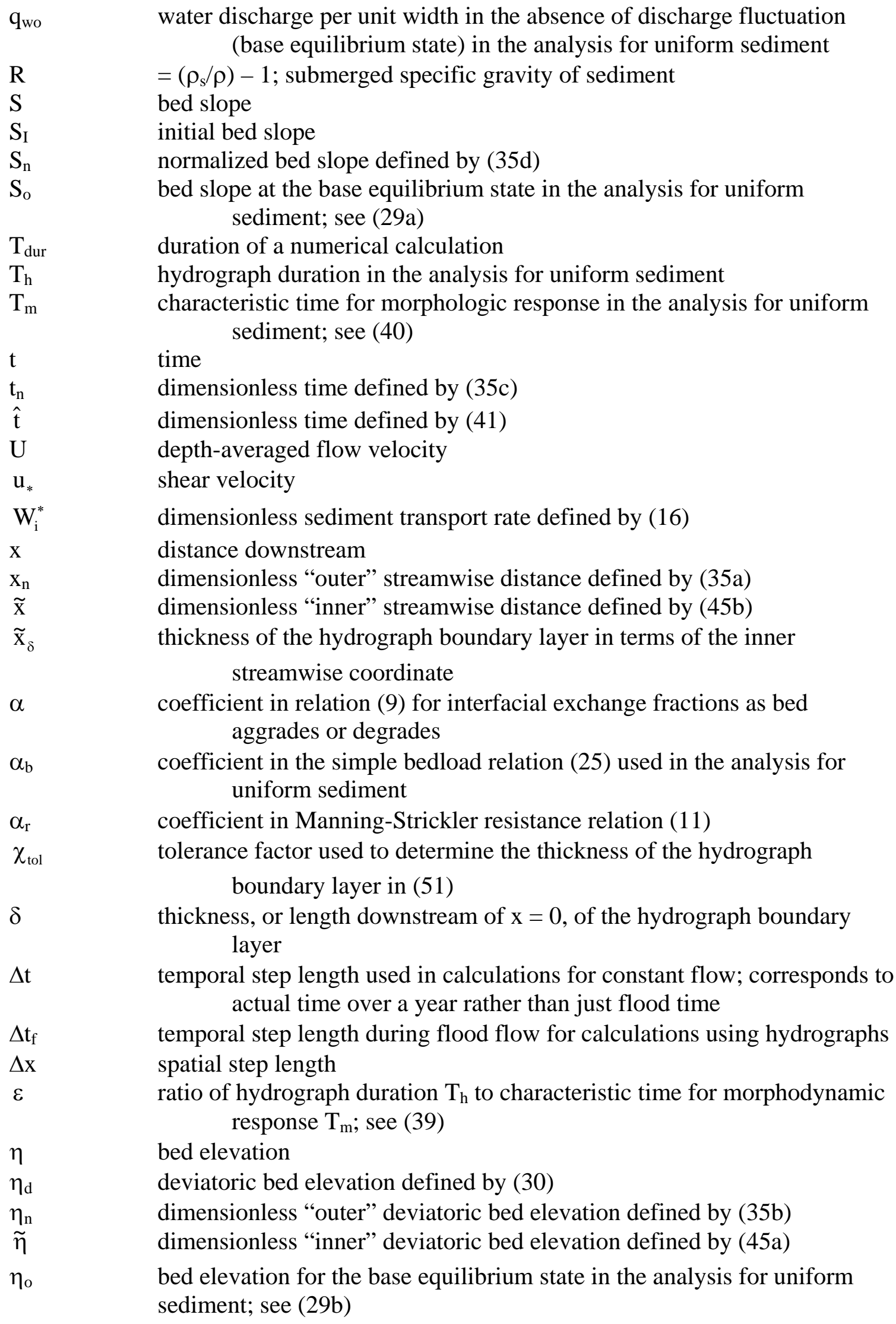


$\eta_{\mathrm{d}}$

$\lambda_{\mathrm{p}}$

$\rho$

$\rho_{\mathrm{s}}$

$\tau_{\mathrm{b}}$

deviatoric bed elevation defined by (30)

porosity of bed deposit

water density

sediment density

boundary shear stress 
TABLE 1. INPUT PARAMETERS FOR THE RUNS WITH A REPEATED HYDROGRAPH

\begin{tabular}{|l|l|l|l|l|l|}
\hline Run & $\mathrm{q}_{\mathrm{bTf}}, \mathrm{m}^{2} / \mathrm{s}$ & $\mathrm{S}_{\mathrm{I}}$ & $\Delta \mathrm{t}_{\mathrm{f}}$, days & $\mathrm{n}_{\text {step }}$ & $\mathrm{T}_{\text {dur, }}$ years \\
\hline $1 \mathrm{H}$ & $1 \times 10^{-1}$ & 0.0263263 & 0.00625 & 80 & 300 \\
\hline $2 \mathrm{H}$ & $3.5 \times 10^{-2}$ & 0.0124 & 0.0125 & 40 & 600 \\
\hline $3 \mathrm{H}$ & $1 \times 10^{-2}$ & 0.00571 & 0.025 & 20 & 1200 \\
\hline $4 \mathrm{H}$ & $3.5 \times 10^{-3}$ & 0.00335 & 0.025 & 20 & 3000 \\
\hline $5 \mathrm{H}$ & $1 \times 10^{-3}$ & 0.00208 & 0.1 & 5 & 3000 \\
\hline $6 \mathrm{H}$ & $3.5 \times 10^{-4}$ & 0.00157 & 0.25 & 2 & 6000 \\
\hline $7 \mathrm{H}$ & $1.5 \times 10^{-4}$ & 0.00133 & 0.5 & 1 & 12000 \\
\hline $8 \mathrm{H}$ & $1 \times 10^{-4}$ & 0.00125 & 0.5 & 1 & 12000 \\
\hline $9 \mathrm{H}$ & $3.5 \times 10^{-5}$ & 0.00112 & 0.5 & 1 & 24000 \\
\hline $10 \mathrm{H}$ & $1 \times 10^{-5}$ & 0.00102 & 0.5 & 1 & 36000 \\
\hline $11 \mathrm{H}$ & $1 \times 10^{-6}$ & 0.000976 & 0.5 & 1 & 120000 \\
\hline
\end{tabular}

TABLE 2. INPUT PARAMETERS FOR THE RUNS WITH AN EQUIVALENT CONSTANT FLOW

\begin{tabular}{|l|l|l|l|l|}
\hline Run & $\mathrm{q}_{\mathrm{bTf}}, \mathrm{m}^{2} / \mathrm{s}$ & $\mathrm{S}_{\mathrm{I}}$ & $\Delta \mathrm{t}$, days & $\mathrm{T}_{\text {dur }}$ years \\
\hline $1 \mathrm{C}$ & $1 \times 10^{-1}$ & 0.0263 & 0.457 & 30 \\
\hline 2C & $3.5 \times 10^{-2}$ & 0.0124 & 1.826 & 120 \\
\hline 3C & $1 \times 10^{-2}$ & 0.00571 & 7.305 & 480 \\
\hline $4 \mathrm{C}$ & $3.5 \times 10^{-3}$ & 0.00335 & 14.61 & 960 \\
\hline $5 \mathrm{C}$ & $1 \times 10^{-3}$ & 0.00208 & 58.44 & 3840 \\
\hline $6 \mathrm{C}$ & $3.5 \times 10^{-4}$ & 0.00157 & 116.88 & 15360 \\
\hline $7 \mathrm{C}$ & $1.5 \times 10^{-4}$ & 0.00133 & 116.88 & 30720 \\
\hline $8 \mathrm{C}$ & $1 \times 10^{-4}$ & 0.00125 & 116.88 & 30720 \\
\hline $9 \mathrm{C}$ & $3.5 \times 10^{-5}$ & 0.00190 & 58.44 & 30720 \\
\hline $10 \mathrm{C}$ & $1 \times 10^{-5}$ & 0.00170 & 58.44 & 30720 \\
\hline $11 \mathrm{C}$ & $1 \times 10^{-6}$ & 0.00150 & 58.44 & 61440 \\
\hline
\end{tabular}




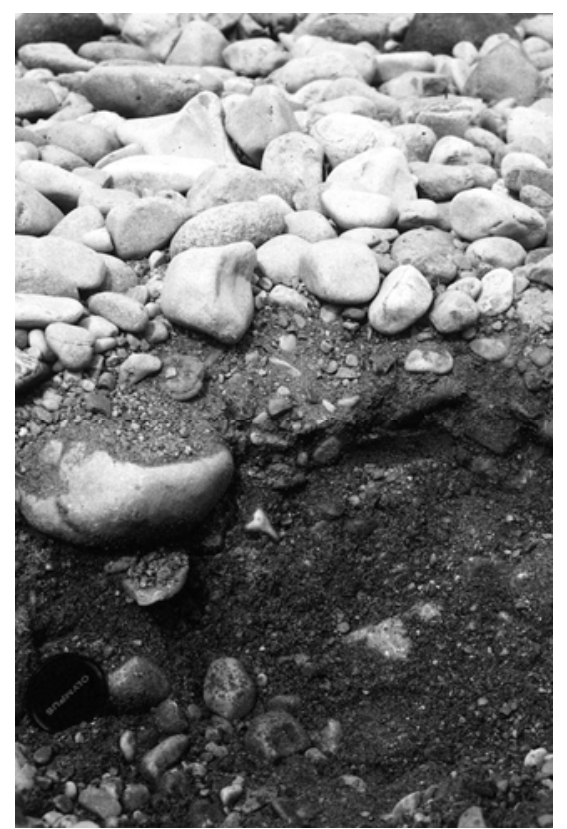

Figure 1. View of the armored bed of the River Wharfe, U.K. Image courtesy D. M. Powell.

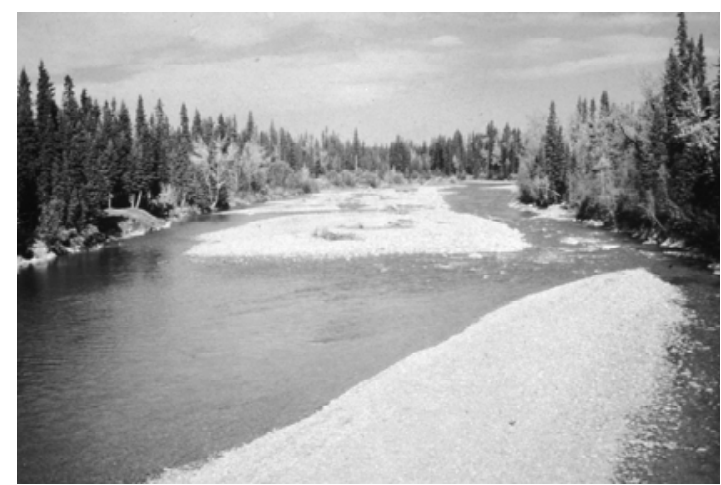

Figure 2a. View of the Elbow River, Canada at low flow. Image courtesy A. B. Hollingshead.

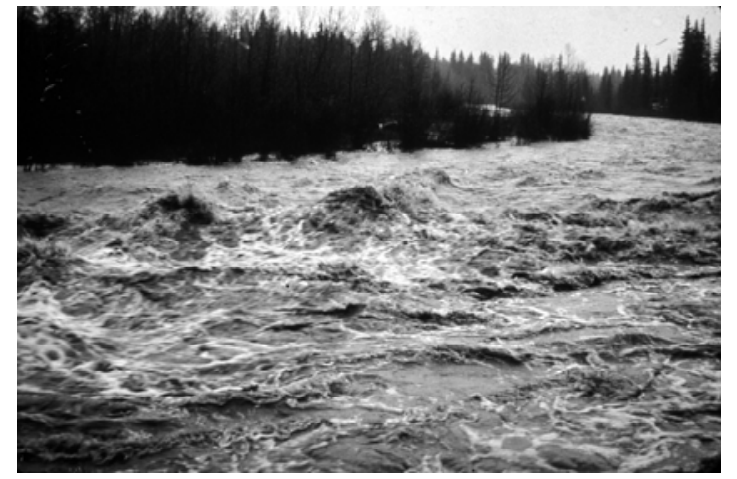

Figure 2b. View of the same reach of the Elbow River, Canada at a flood estimated to be a 100-year recurrence flood. Image courtesy A. B. Hollingshead 


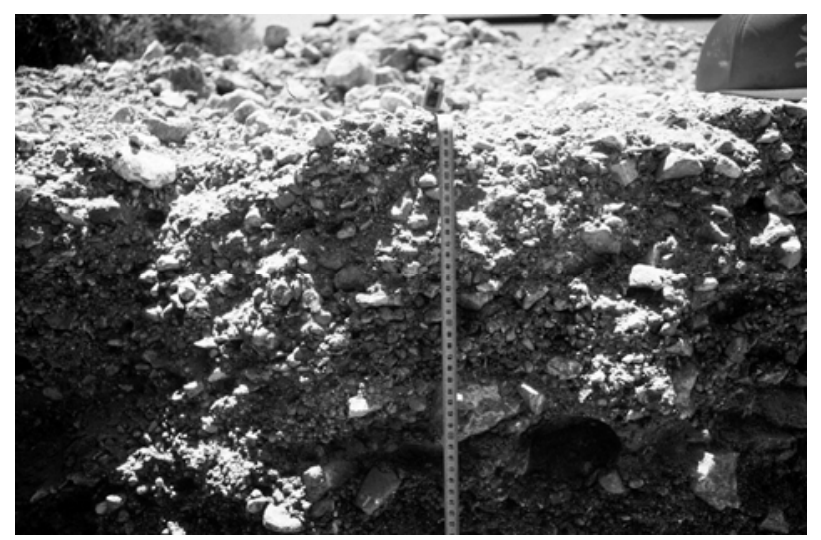

Figure 3. View of the unarmored bed of the Nahal Yatir, Israel. Image courtesy D. M. Powell.

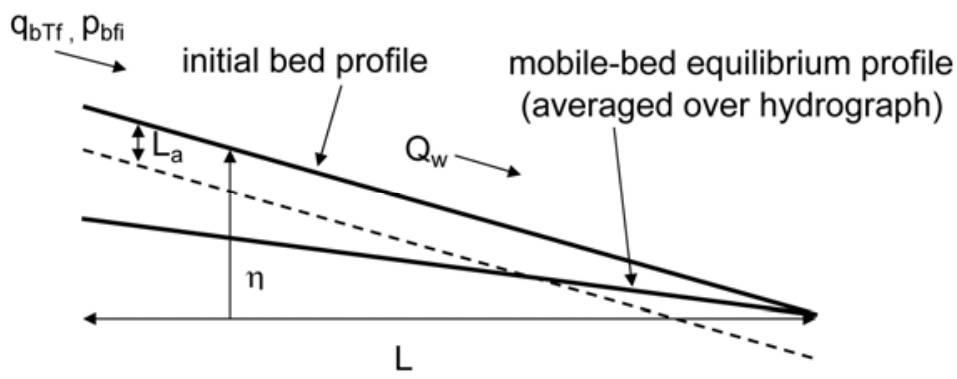

Figure 4. Schematic diagram of the configuration for the numerical experiments with sediment mixtures. 


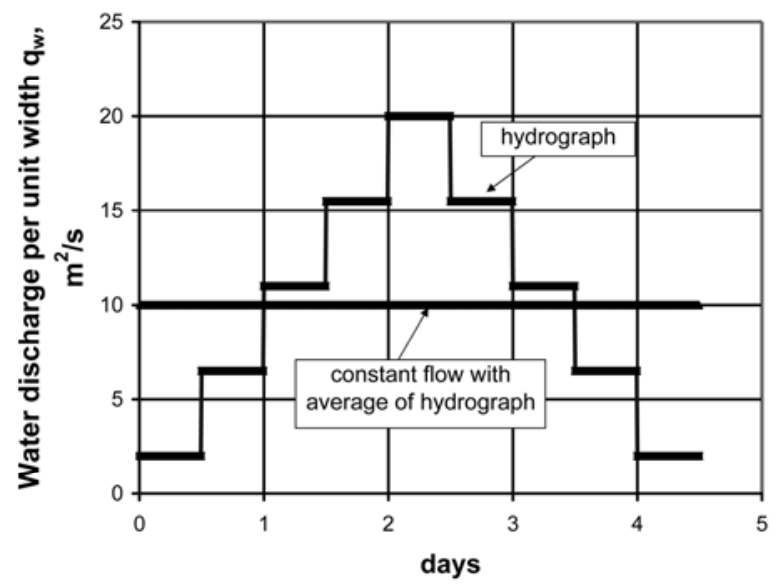

Figure 5. Plot of the 4.5-day hydrograph used in the runs of Table 1, and the 4.5-day period of constant flow with the average water discharge per unit width of the hydrograph used in the runs of Table 2. Each 4.5-day flow (hydrograph or constant flow) was repeated once per year.

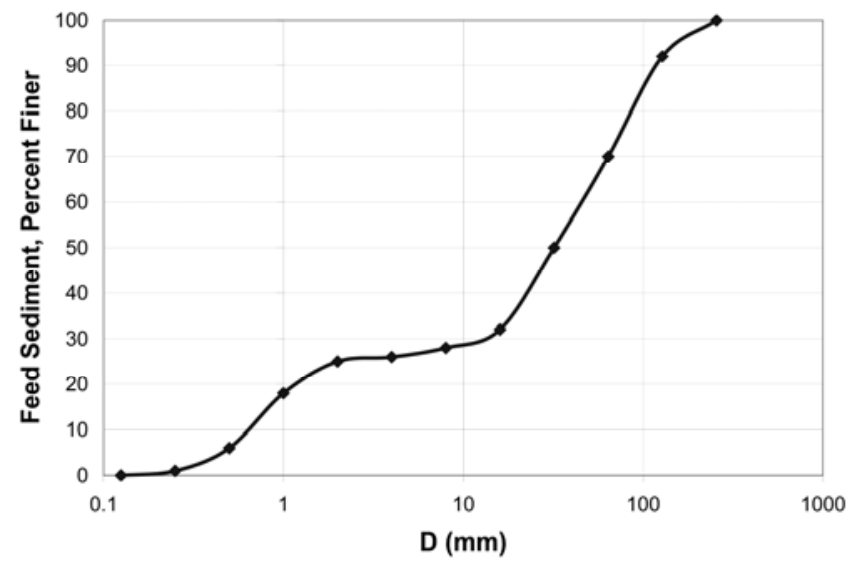

Figure 6. Grain size distribution of the feed sediment. The same grain size distribution was used for the initial surface and substrate size distributions. 


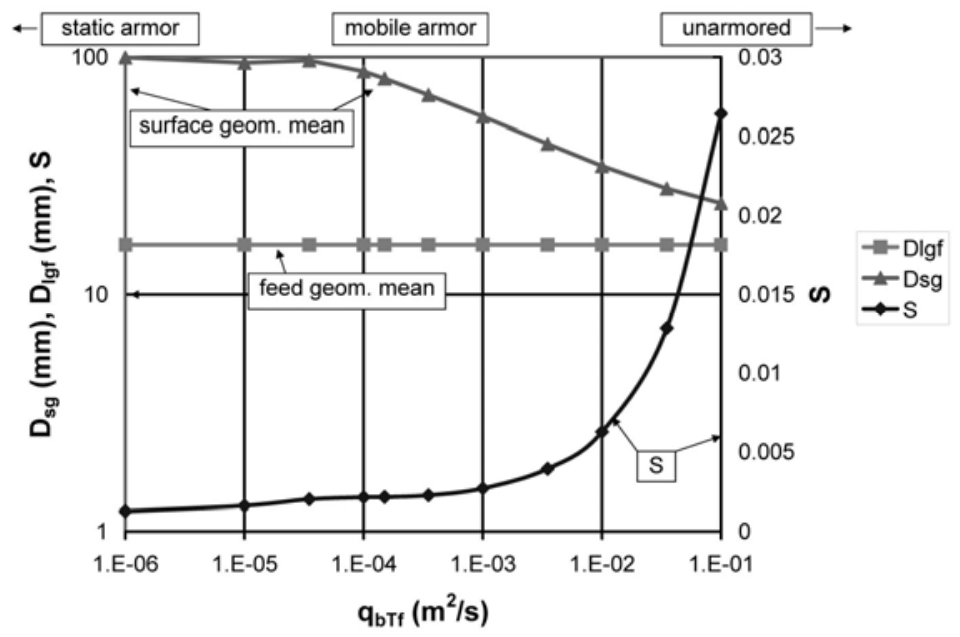

Figure 7. Plot of surface geometric mean size $\mathrm{D}_{\text {sg }}$ and bed slope $\mathrm{S}$ as functions of the volume bedload feed rate per unit width $\mathrm{q}_{\mathrm{bTf}}$ for the runs of Table 2, i.e. constant flow. The parameters pertain to mobile-bed equilibrium. Also shown is the geometric mean size $\mathrm{D}_{\text {lgf }}$ of the feed sediment, which is held constant in all runs.

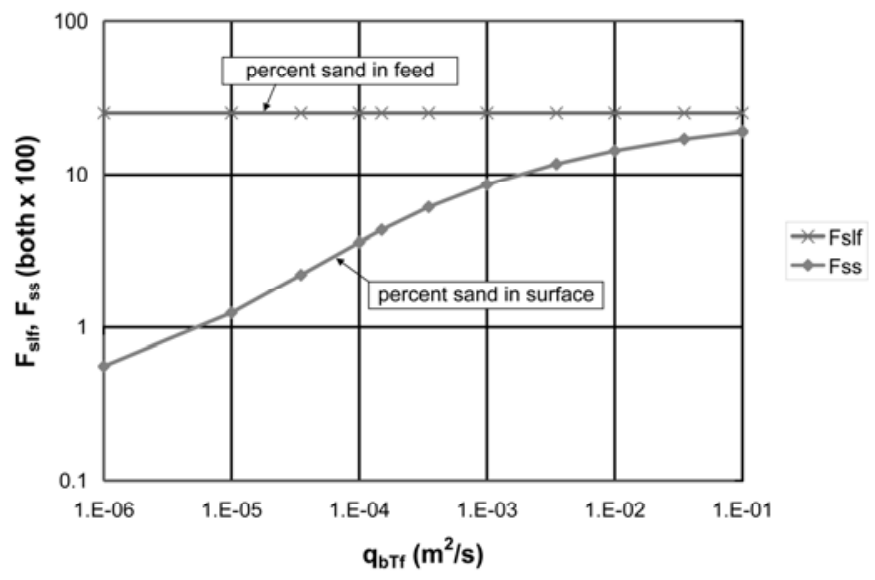

Figure 8. Plot of the fraction of sand $F_{s s}$ in the surface layer as a function of volume bedload feed rate per unit width $\mathrm{q}_{\mathrm{bTf}}$ for the runs of Table 2, i.e. constant flow. The parameters pertain to mobile-bed equilibrium. Also shown is the fraction of sand $F_{\text {slf }}$ in the feed sediment, which is held in all runs. 


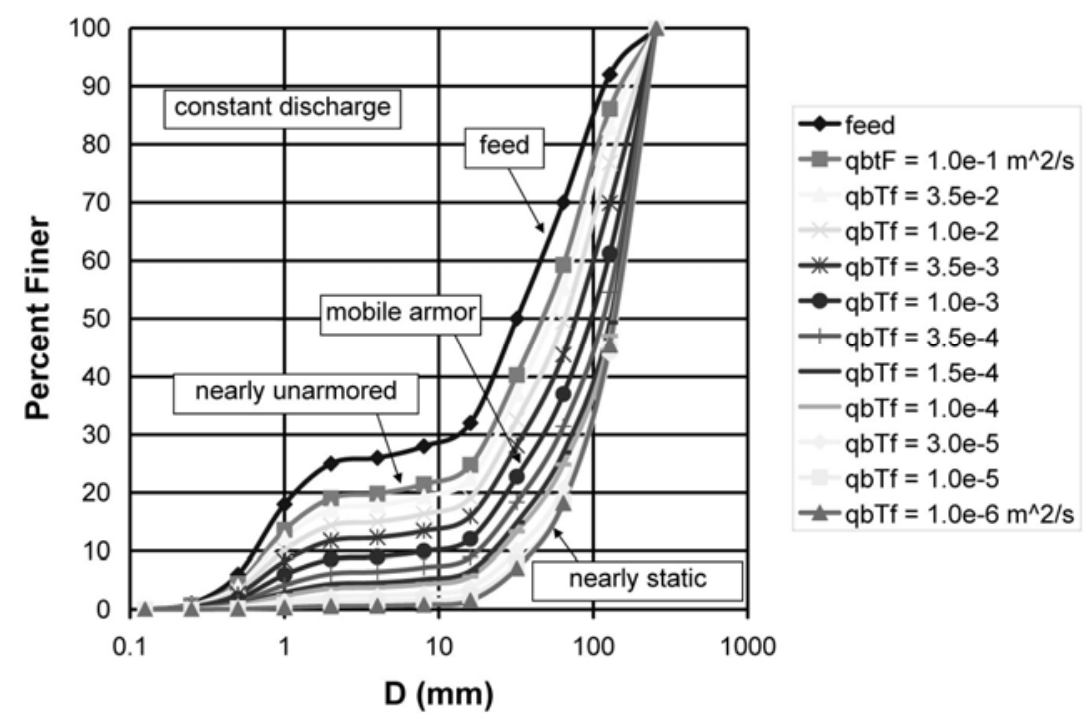

Figure 9. Surface grain size distributions at mobile-bed equilibrium for all the constantflow runs of Table 2. The bedload feed rates $\mathrm{q}_{\mathrm{bTf}}$ are specified in $\mathrm{m}^{2} / \mathrm{s}$. Also shown is the grain size distribution of the feed sediment, which is held constant in all runs.

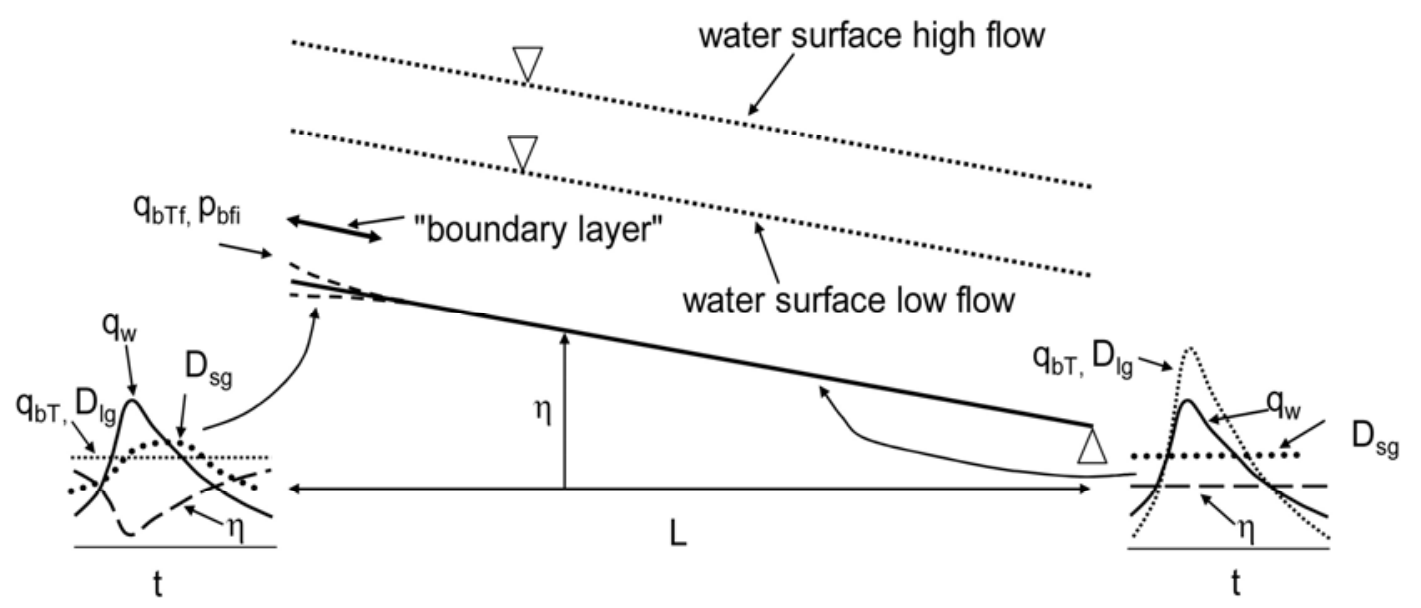

Figure 10. Diagram illustrating the essential results of the numerical runs with a cycled hydrograph of Table 1 . At the upstream end of the reach the total volume feed rate per unit width $\mathrm{q}_{\mathrm{b}}$ and the geometric mean size of the load $\mathrm{D}_{\mathrm{lg}}$ are held constant, but flow discharge per unit width $\mathrm{q}_{\mathrm{w}}$ is allowed to vary cyclically. In a short hydrograph boundary layer downstream, bed elevation $\eta$ and surface geometric mean grain $\mathrm{D}_{\mathrm{sg}}$ vary cyclically as well. Downstream of this boundary layer $\eta$ and $D_{\text {sg }}$ become invariant with time, and $\mathrm{q}_{\mathrm{bT}}$ and $\mathrm{D}_{\mathrm{lg}}$ now vary cyclically in time with the flow hydrograph. The diagram pertains to mobile-bed equilibrium. 


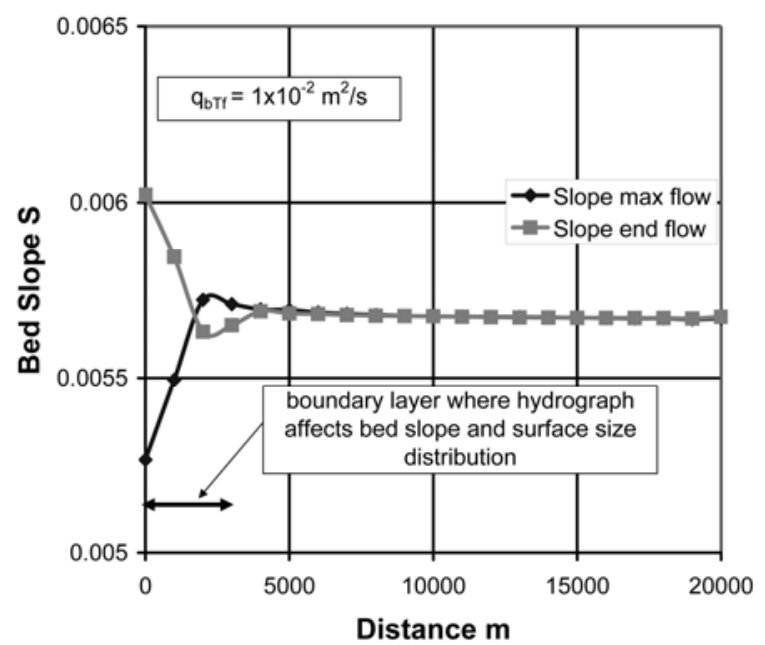

Figure 11. Bed slope profiles for the maximum (peak) flow and the minimum (end) flow of the last hydrograph of Run $3 \mathrm{H}$. Mobile-bed equilibrium has been achieved by this time. Bed slope fluctuates with the hydrograph only in a short region (hydrograph boundary layer) near the feed point $(\mathrm{x}=0)$.

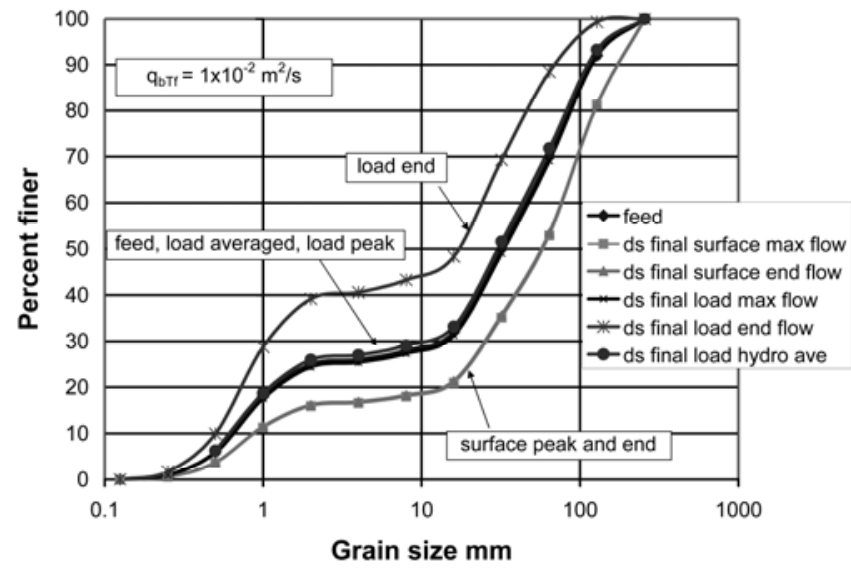

Figure 12. Grain size distributions of the surface material and bedload at the maximum (peak) and minimum (end) flows of the last hydrograph of Run $3 \mathrm{H}$. Also included are the grain size distributions of the feed sediment and the bedload averaged over the hydrograph. The node in question is the one farthest downstream $(x=L)$. Note that the surface size distribution is nearly invariant, whereas the bedload size distribution varies strongly between the peak and end flows. 


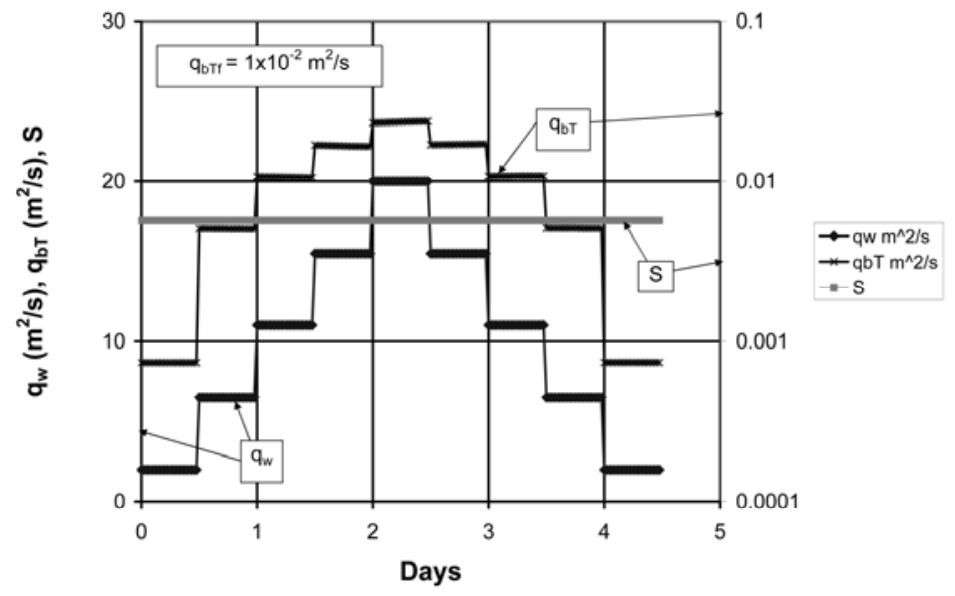

Figure 13a. Plot of the variation of water discharge per unit width $\mathrm{q}_{\mathrm{w}}$, bed slope $\mathrm{S}$ and volume bedload transport rate per unit width $\mathrm{q}_{\mathrm{bT}}$ with time over the last hydrograph, at the node farthest downstream ( $\mathrm{x}=\mathrm{L})$, for Run $3 \mathrm{H}$. Note that slope $\mathrm{S}$ is invariant over the hydrograph, but the time variation in the bedload transport rate $\mathrm{q}_{\mathrm{bT}}$ tracks that of the water discharge per unit width $\mathrm{q}_{\mathrm{w}}$.

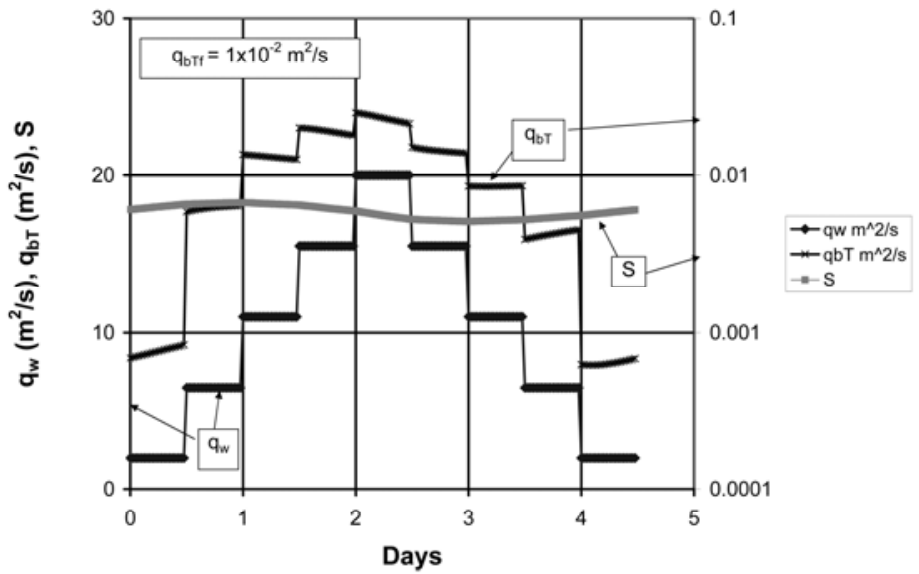

Figure 13b. Plot of the variation of water discharge per unit width $\mathrm{q}_{\mathrm{w}}$, bed slope $\mathrm{S}$ and volume bedload transport rate per unit width $\mathrm{q}_{\mathrm{bT}}$ with time over the last hydrograph, at the node farthest upstream $(x=0)$, for Run $3 H$. Note that slope $S$ and the bedload transport rate $\mathrm{q}_{\mathrm{bT}}$ both vary in time over the hydrograph. 


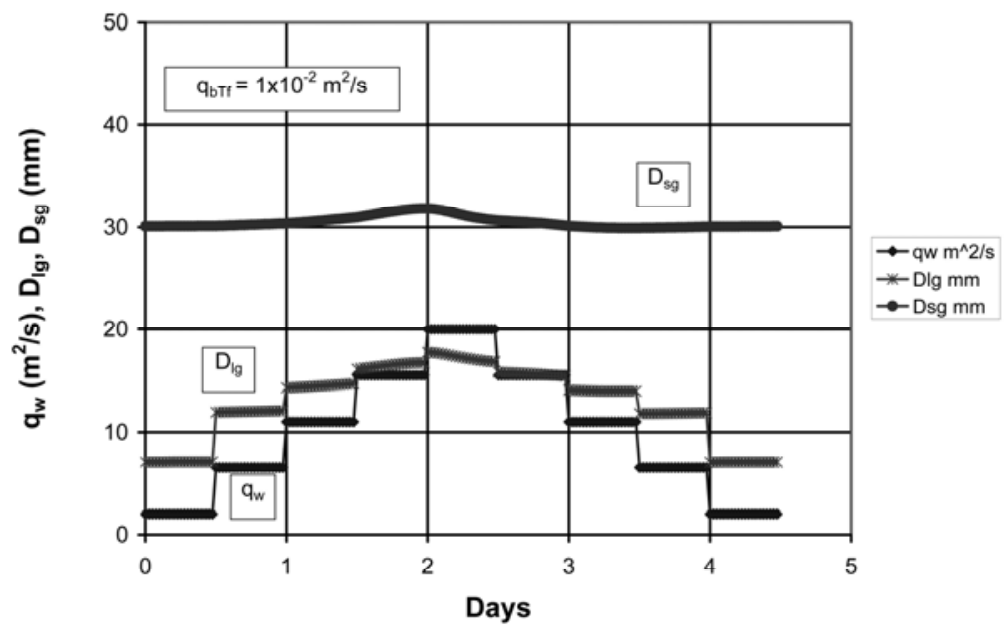

Figure 14a. Plot of the variation of water discharge per unit width $\mathrm{q}_{\mathrm{w}}$, load geometric mean size $\mathrm{D}_{\lg }$ and surface geometric mean size $\mathrm{D}_{\text {sg }}$ with time over the last hydrograph, at the node farthest downstream $(x=L)$, for Run $3 \mathrm{H}$. Note that load geometric mean size $D_{\lg }$ varies strongly in time over the hydrograph, whereas surface geometric mean size $D_{\text {sg }}$ is nearly invariant.

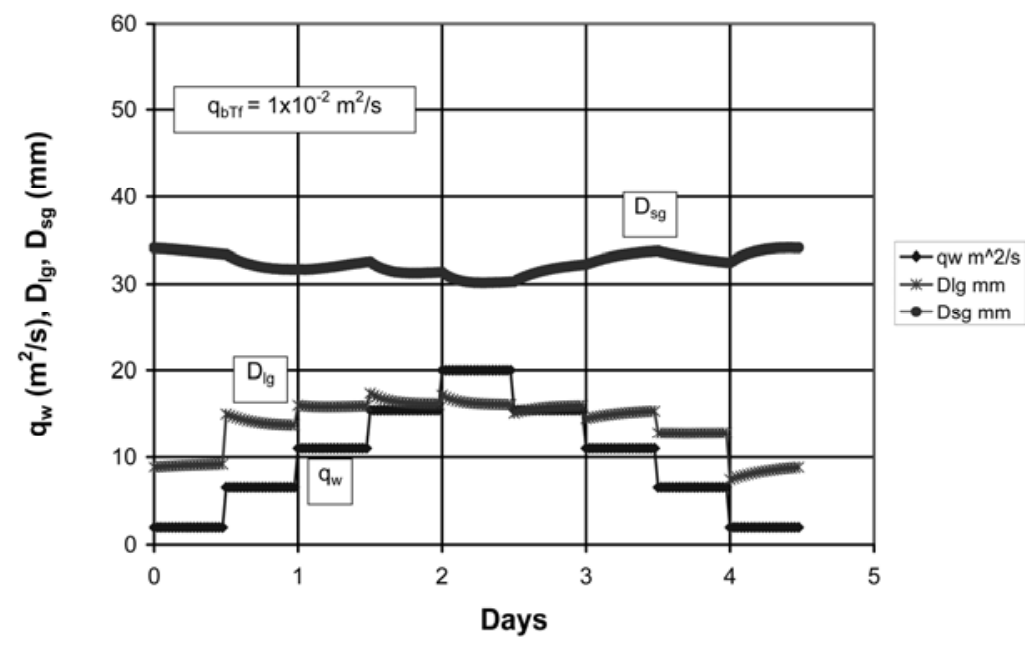

Figure 14b. Plot of the variation of water discharge per unit width $\mathrm{q}_{\mathrm{w}}$, load geometric mean size $\mathrm{D}_{\lg }$ and surface geometric mean size $\mathrm{D}_{\text {sg }}$ with time over the last hydrograph, at the node farthest upstream $(x=0)$, for Run $3 \mathrm{H}$. Note that both surface geometric mean size $\mathrm{D}_{\mathrm{sg}}$ and load geometric mean size $\mathrm{D}_{\mathrm{lg}}$ vary notably over the hydrograph. 


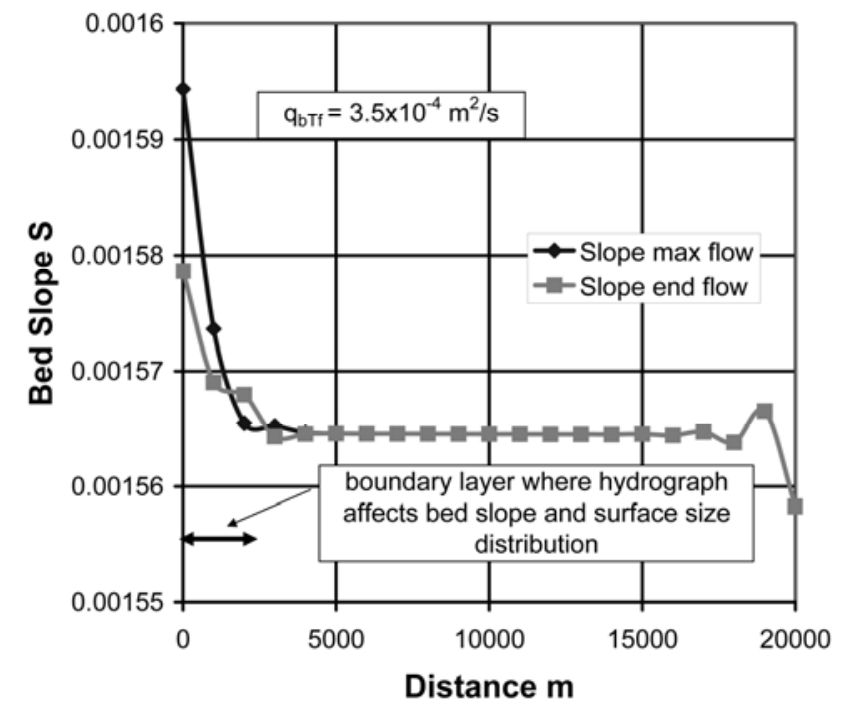

Figure 15. Bed slope profiles for the maximum (peak) flow and the minimum (end) flow of the last hydrograph of Run $6 \mathrm{H}$. Mobile-bed equilibrium has been achieved by this time. Bed slope fluctuates with the hydrograph only in a short region near the feed point $(\mathrm{x}=0)$. The hydrograph boundary layer is somewhat shorter than in the case of Figure 13 (Run $3 \mathrm{H}$ ). The very small streamwise variation in bed slope near $\mathrm{x}=\mathrm{L}$ is an artifact of the model.

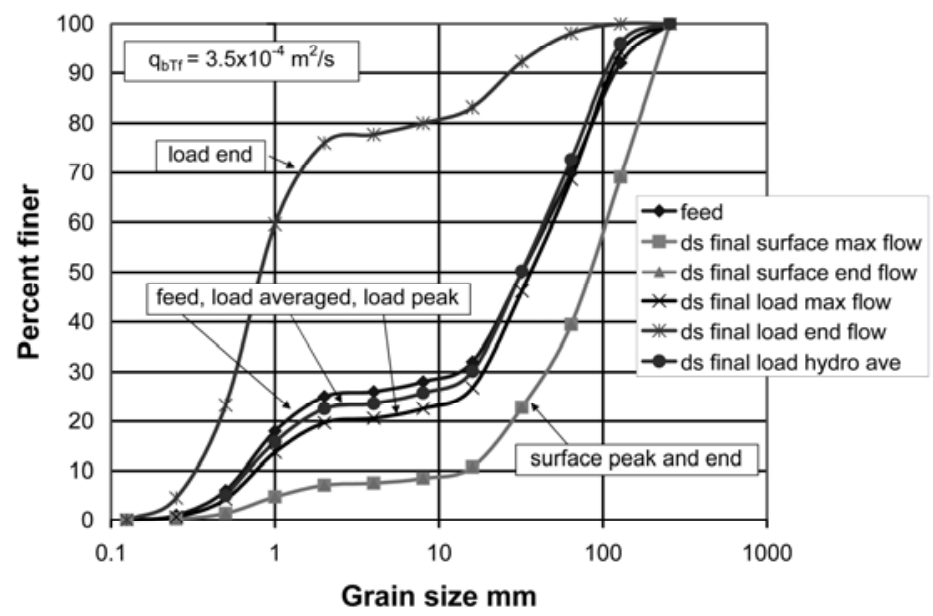

Figure 16. Grain size distributions of the surface material and bedload at the maximum (peak) and minimum (end) flows of the last hydrograph of Run $6 \mathrm{H}$. Also included are the grain size distributions of the feed sediment and the bedload averaged over the hydrograph. The node in question is the one farthest downstream $(x=L)$. Note that the surface size distribution is invariant, whereas the bedload size distribution varies strongly between the peak and end flow. 


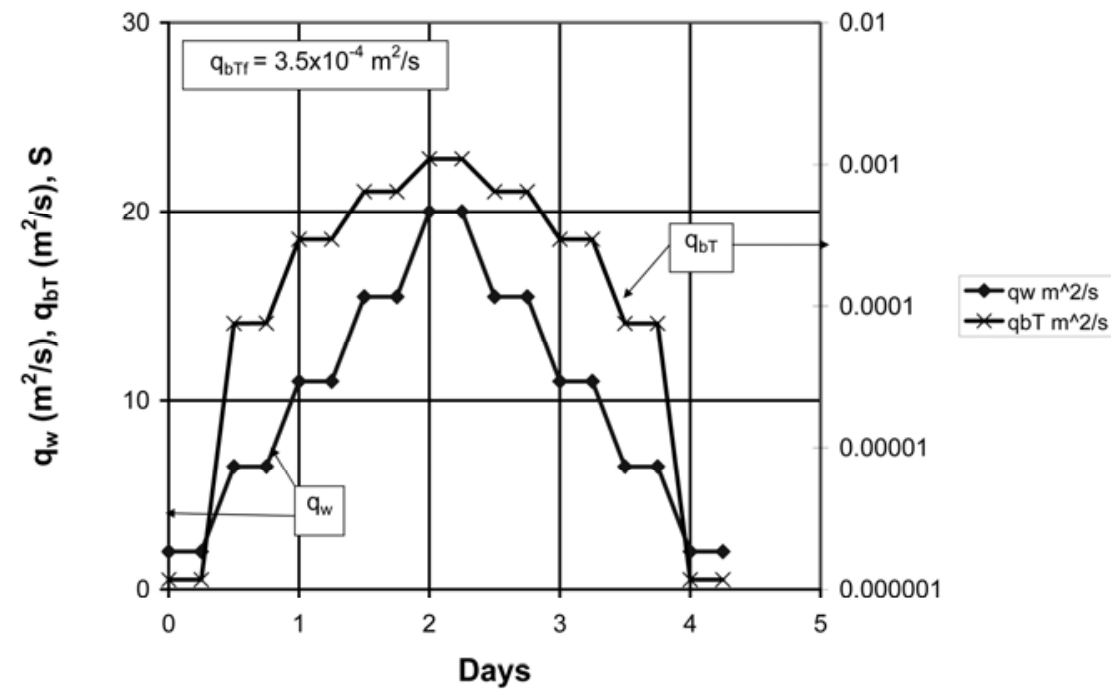

Figure 17a. Plot of the variation of water discharge per unit width $\mathrm{q}_{w}$ and volume bedload transport rate per unit width $\mathrm{q}_{\mathrm{bT}}$ with time over the last hydrograph, at the node farthest downstream $(\mathrm{x}=\mathrm{L})$, for Run $6 \mathrm{H}$. The time variation in the bedload transport rate $\mathrm{q}_{\mathrm{bT}}$ tracks that of the water discharge per unit width $\mathrm{q}_{\mathrm{w}}$.

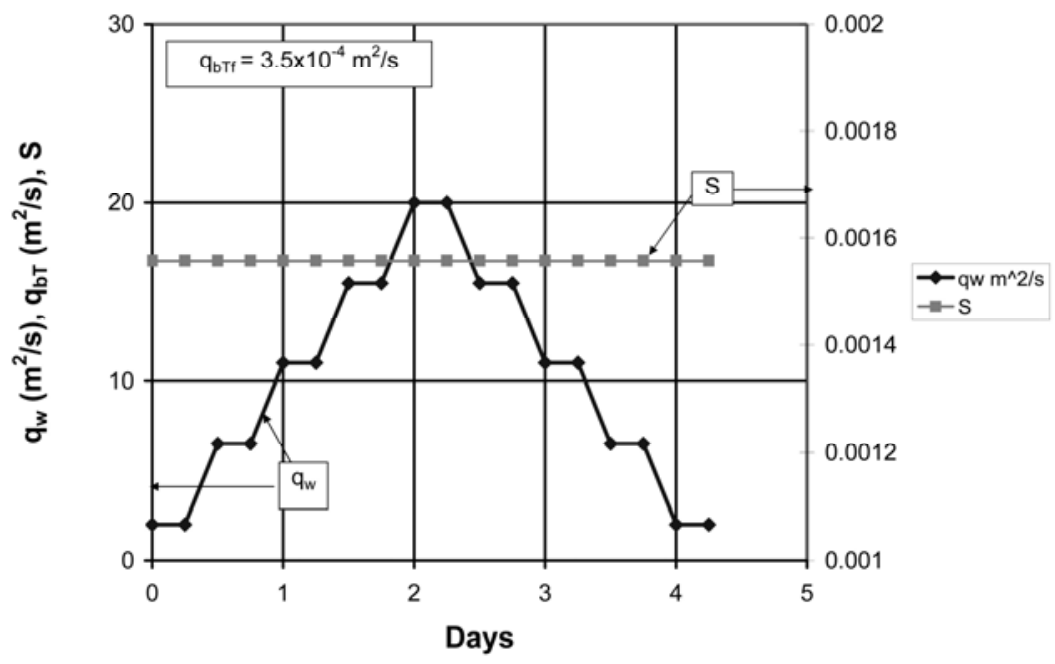

Figure 17b. Plot of the variation of water discharge per unit width $\mathrm{q}_{\mathrm{w}}$ and bed slope $\mathrm{S}$ with time over the last hydrograph, at the node farthest downstream $(x=L)$, for Run $6 \mathrm{H}$. Note that slope $\mathrm{S}$ is invariant over the hydrograph. 


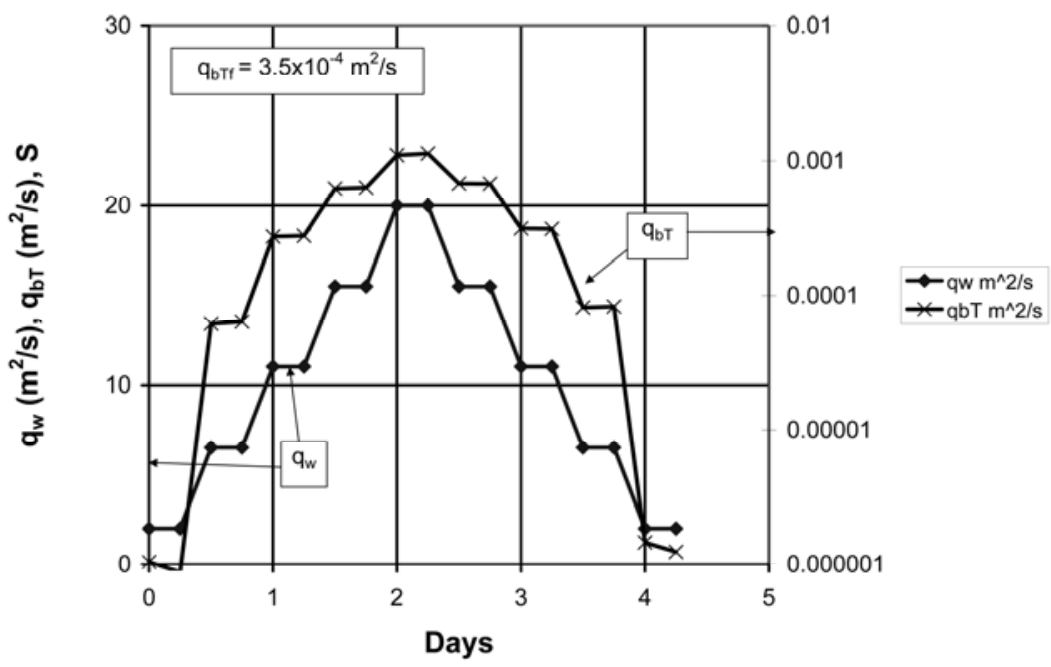

Figure 17c. Plot of the variation of water discharge per unit width $\mathrm{q}_{w}$ and volume bedload transport rate per unit width $\mathrm{q}_{\mathrm{b} \text { т }}$ with time over the last hydrograph, at the node farthest upstream $(x=0)$, for Run $6 \mathrm{H}$. The time variation in the bedload transport rate $\mathrm{q}_{\mathrm{bT}}$ tracks that of the water discharge per unit width $\mathrm{q}_{\mathrm{w}}$.

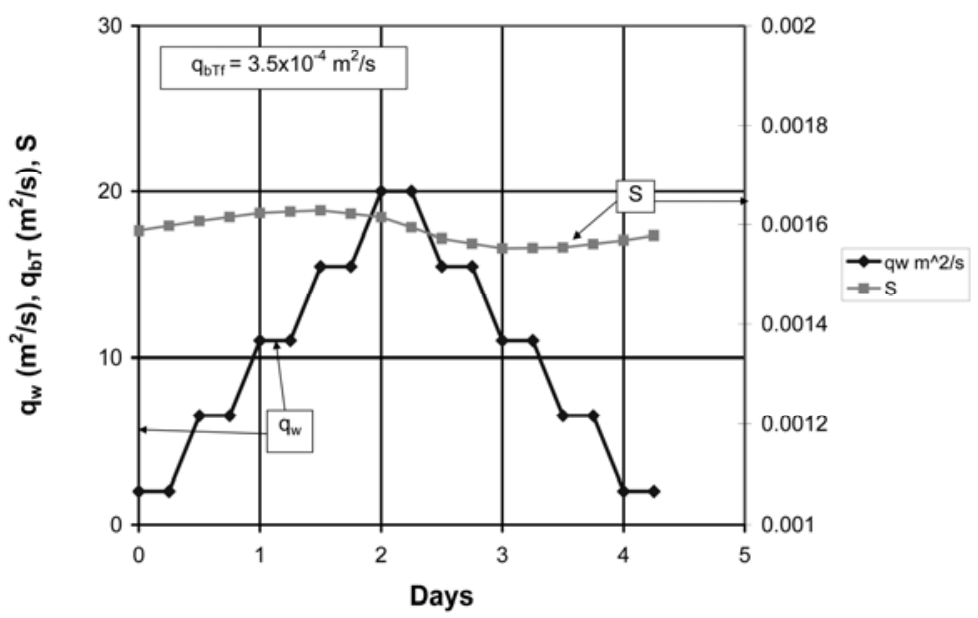

Figure 17d. Plot of the variation of water discharge per unit width $\mathrm{q}_{\mathrm{w}}$ and bed slope $\mathrm{S}$ with time over the last hydrograph, at the node farthest upstream $(\mathrm{x}=0)$, for Run $6 \mathrm{H}$. Note that slope $\mathrm{S}$ varies over the hydrograph. 


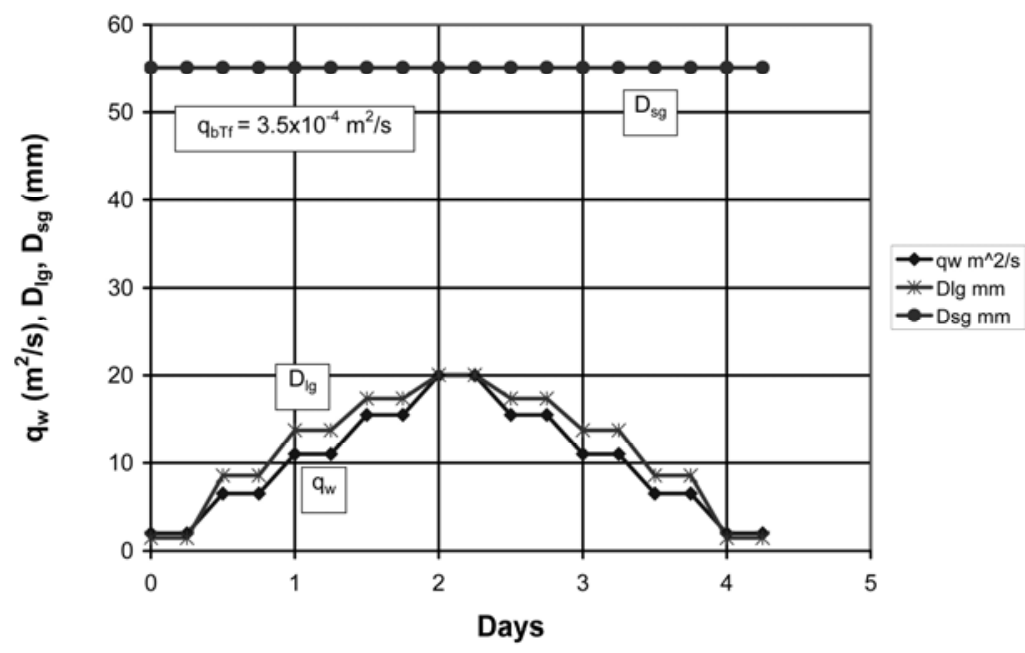

Figure 18a. Plot of the variation of water discharge per unit width $\mathrm{q}_{\mathrm{w}}$, load geometric mean size $D_{\lg }$ and surface geometric mean size $D_{\text {sg }}$ with time over the last hydrograph, at the node farthest downstream $(x=\mathrm{L})$, for Run $6 \mathrm{H}$. Note that load geometric mean size $D_{\text {lg }}$ varies strongly in time over the hydrograph, whereas surface geometric mean size $D_{\text {sg }}$ is invariant.

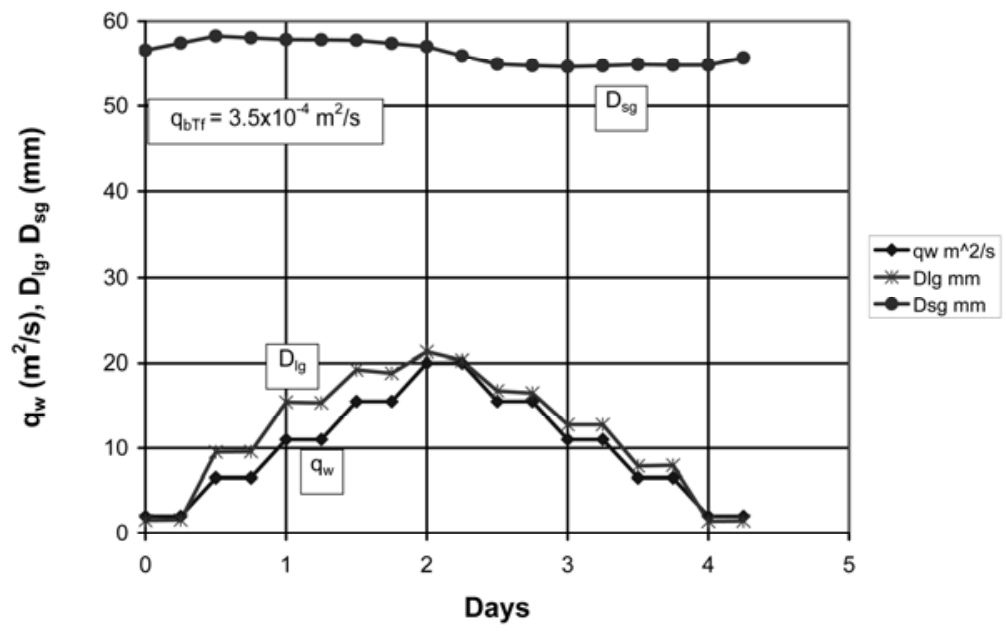

Figure 18b. Plot of the variation of water discharge per unit width $\mathrm{q}_{\mathrm{w}}$, load geometric mean size $\mathrm{D}_{\lg }$ and surface geometric mean size $\mathrm{D}_{\text {sg }}$ with time over the last hydrograph, at the node farthest upstream $(\mathrm{x}=0)$, for Run $6 \mathrm{H}$. Note that both surface geometric mean size $\mathrm{D}_{\mathrm{sg}}$ and load geometric mean size $\mathrm{D}_{\mathrm{lg}}$ vary notably over the hydrograph. 


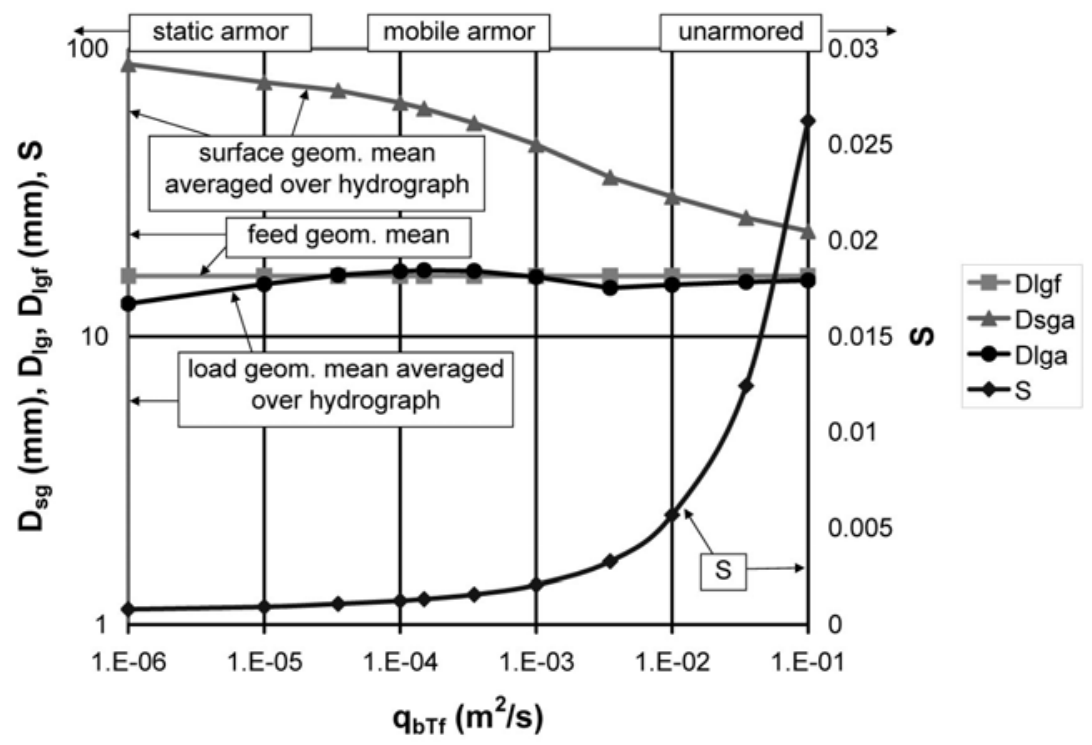

Figure 19. Plot of surface geometric mean size averaged over the hydrograph $\mathrm{D}_{\text {sga, }}$, bedload geometric mean size averaged over the hydrograph $D_{\text {lga }}$ and bed slope $S$ as functions of the volume bedload feed rate per unit width $\mathrm{q}_{\mathrm{bTf}}$ for the hydrograph runs of Table 1. The parameters pertain to mobile-bed equilibrium at the node farthest downstream $(\mathrm{x}=\mathrm{L})$. Also shown is the geometric mean size $\mathrm{D}_{\operatorname{lgf}}$ of the feed sediment.

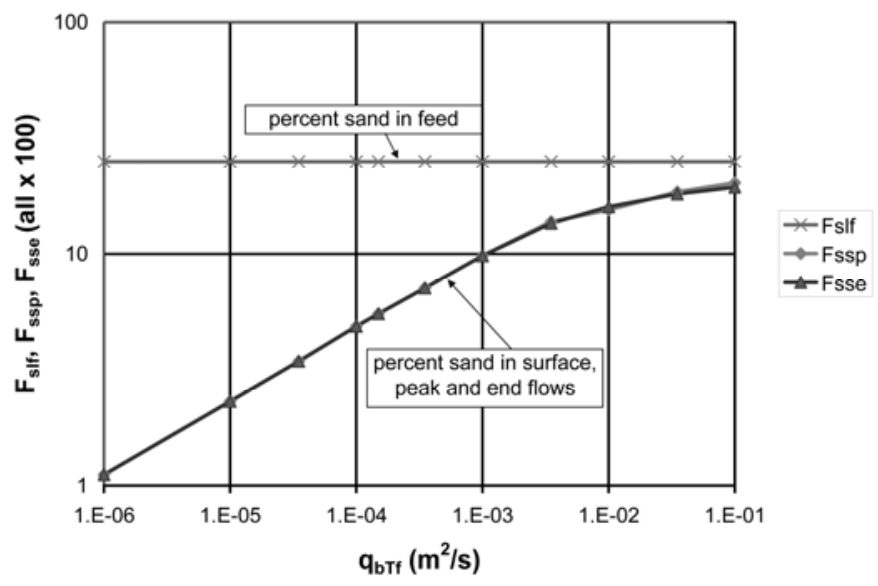

Figure 20. Plot of the fraction of sand in the surface $F_{\text {ssp }}$ at the maximum (peak) flow and fraction of sand in the surface $F_{\text {sse }}$ at the minimum (end) flow as functions of volume bedload feed rate per unit width $\mathrm{q}_{\mathrm{bTf}}$ for the runs of Table 1, i.e. cycled hydrograph. The parameters pertain to mobile-bed equilibrium at the node farthest downstream $(x=L)$. Also shown is the fraction of sand $F_{\text {slf }}$ in the feed sediment. 


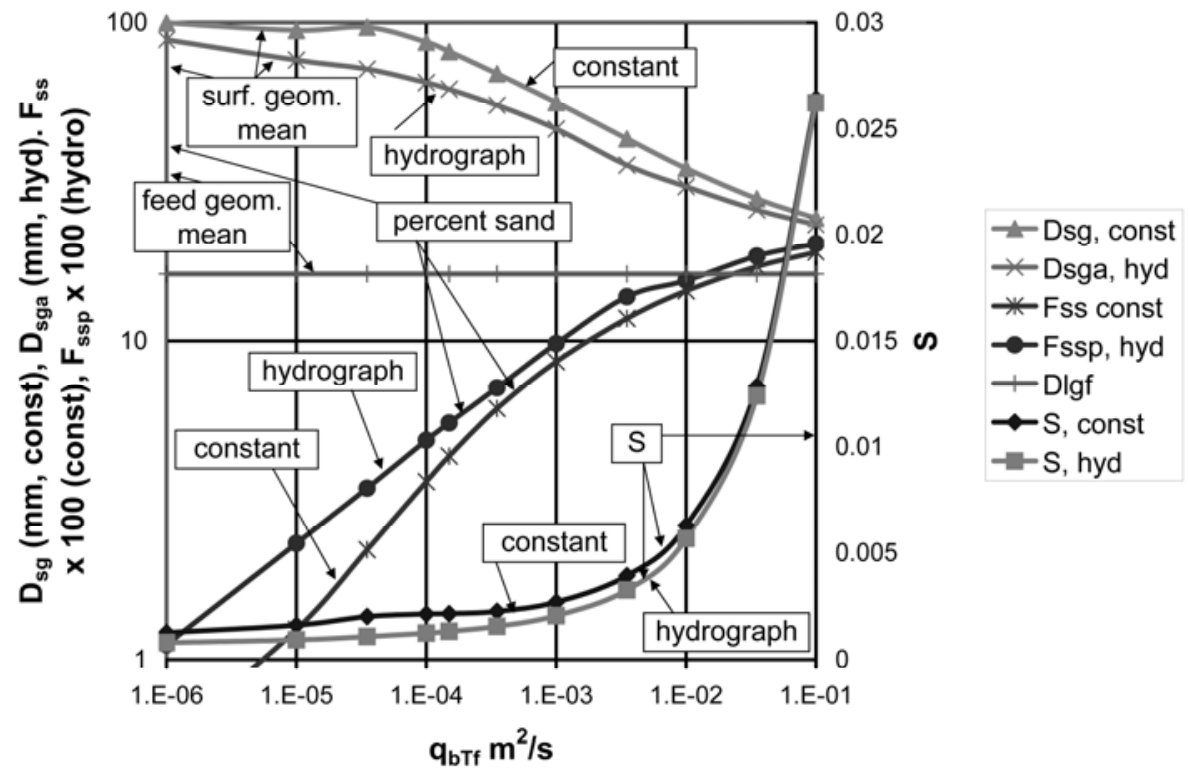

Figure 21. Plots of the following parameters at mobile-bed equilibrium as functions of volume bedload feed rate per unit width $\mathrm{q}_{\mathrm{bTf}}$ : bed slope $\mathrm{S}$ for both the hydrograph runs of Table 1 and constant-flow runs of Table 2; fraction of sand in the surface layer $F_{\mathrm{ss}}$ for the runs of Table 2; fraction of sand in the surface layer at the maximum (peak) flow $\mathrm{F}_{\mathrm{ssp}}$ for the runs of Table 1; surface geometric mean size $D_{\text {sg }}$ for the runs of Table 2; surface geometric mean size averaged over the hydrograph $\mathrm{D}_{\text {sga }}$ for the runs of Table 1. Also shown for reference is the geometric mean size of the feed sediment $\mathrm{D}_{\text {lgf. }}$

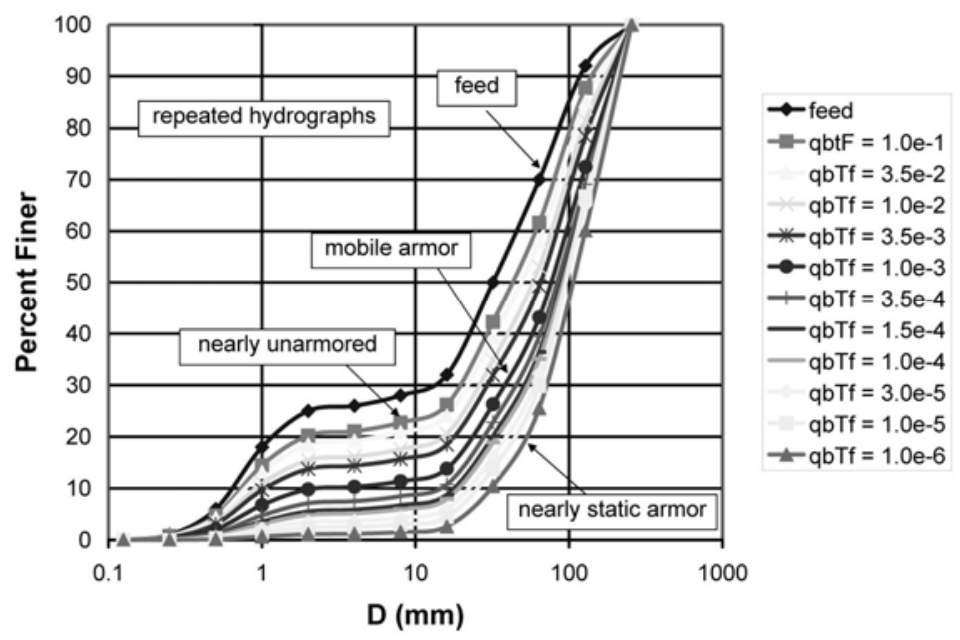

Figure 22. Surface grain size distributions at mobile-bed equilibrium for all the hydrograph runs of Table 1 . The bedload feed rates $q_{b T f}$ are specified in $\mathrm{m}^{2} / \mathrm{s}$. Also shown is the grain size distribution of the feed sediment. The data pertain to the node farthest downstream $(\mathrm{x}=\mathrm{L})$. 


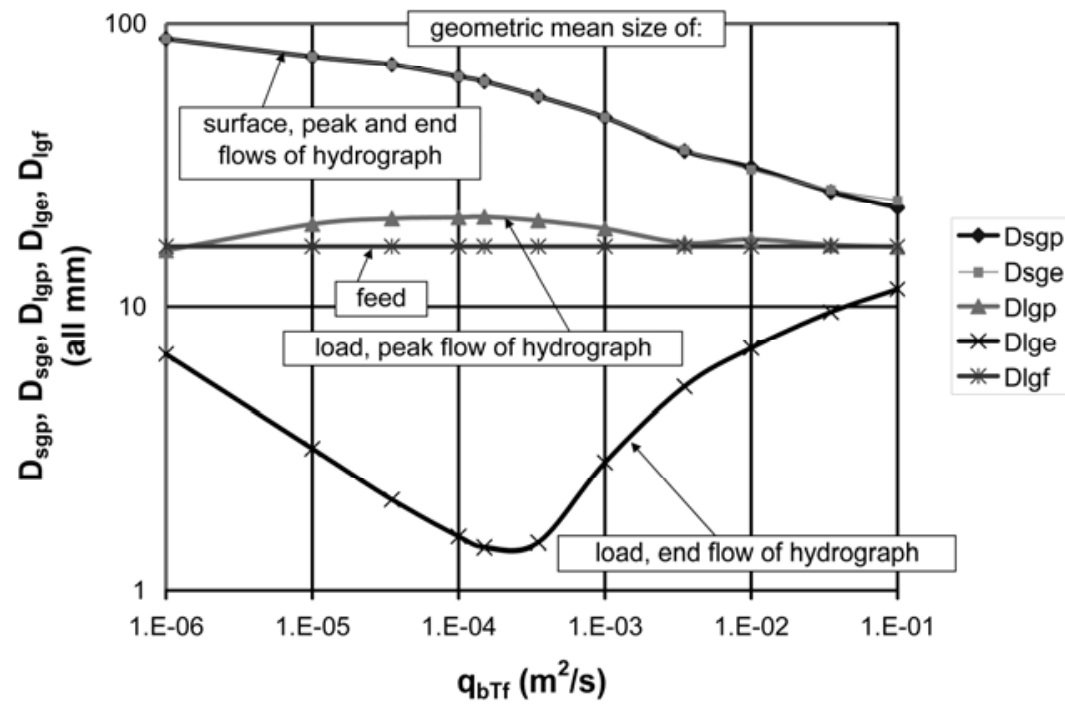

Figure 23. Plots of surface and bedload geometric mean sizes $\mathrm{D}_{\mathrm{sgp}}$ and $\mathrm{D}_{\text {lgp }}$, respectively, at maximum (peak) flow, and surface and bedload geometric mean sizes $\mathrm{D}_{\text {sge }}$ and $\mathrm{D}_{\text {lge, }}$, respectively, at minimum (end) flow for the hydrograph runs of Table 1. The values pertain to mobile-bed equilibrium at the farthest node downstream $(x=L)$. Also shown for reference is the geometric mean size of the feed sediment $\mathrm{D}_{\text {lgf. }}$

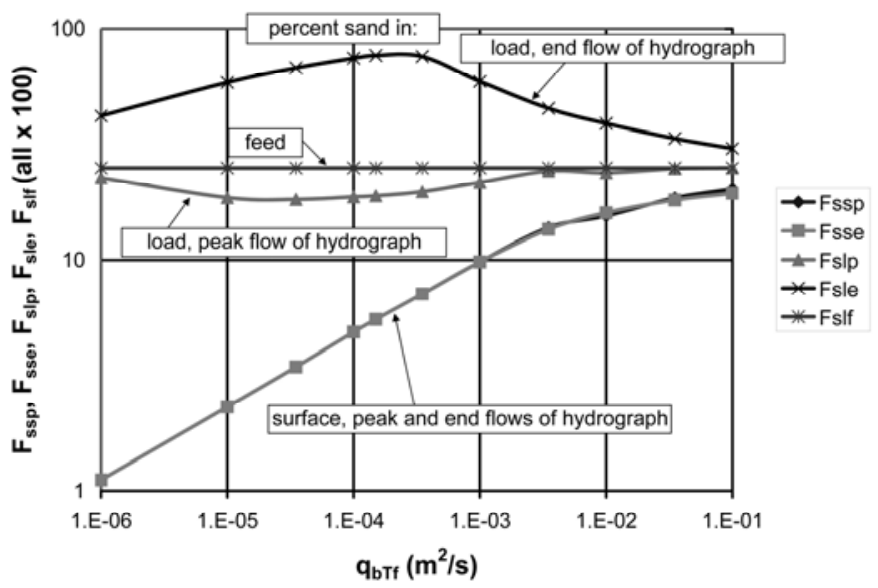

Figure 24. Plots of fraction of sand in the surface and bedload $\mathrm{F}_{\mathrm{ssp}}$ and $\mathrm{F}_{\mathrm{slp}}$, respectively, at maximum (peak) flow, and fraction of sand in the surface and bedload $\mathrm{F}_{\text {sse }}$ and $\mathrm{F}_{\text {sle }}$ at minimum (end flow) for the hydrograph runs of Table 1. The values pertain to mobilebed equilibrium at the farthest node downstream $(\mathrm{x}=\mathrm{L})$. Also shown for reference is the fraction of sand $\mathrm{F}_{\text {slf }}$ in the feed sediment. 


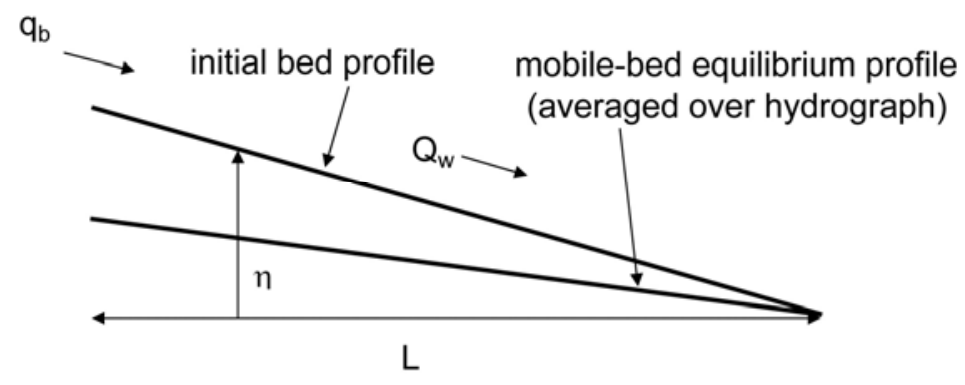

Figure 25. Schematic diagram of the configuration for the numerical experiments with uniform sediment.

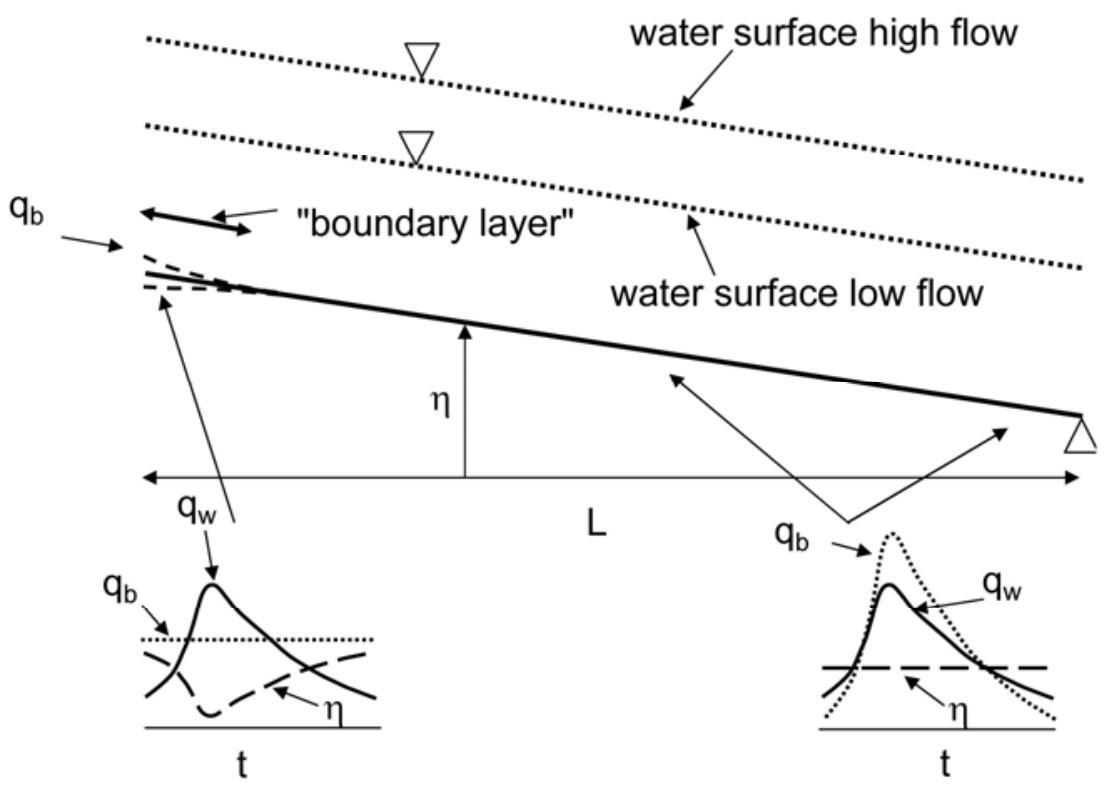

Figure 26. Diagram illustrating the expected behavior for numerical experiments with uniform sediment. At the upstream end of the reach the volume bedload feed rate per unit width $\mathrm{q}_{\mathrm{b}}$ is held constant, but flow discharge per unit width $\mathrm{q}_{\mathrm{w}}$ is allowed to vary cyclically. In a short hydrograph boundary layer downstream bed elevation $\eta$ varies cyclically as well. Downstream of this boundary layer $\eta$ becomes invariant with time, and $q_{b}$ now varies cyclically with the flow hydrograph. The diagram pertains to mobilebed equilibrium. 


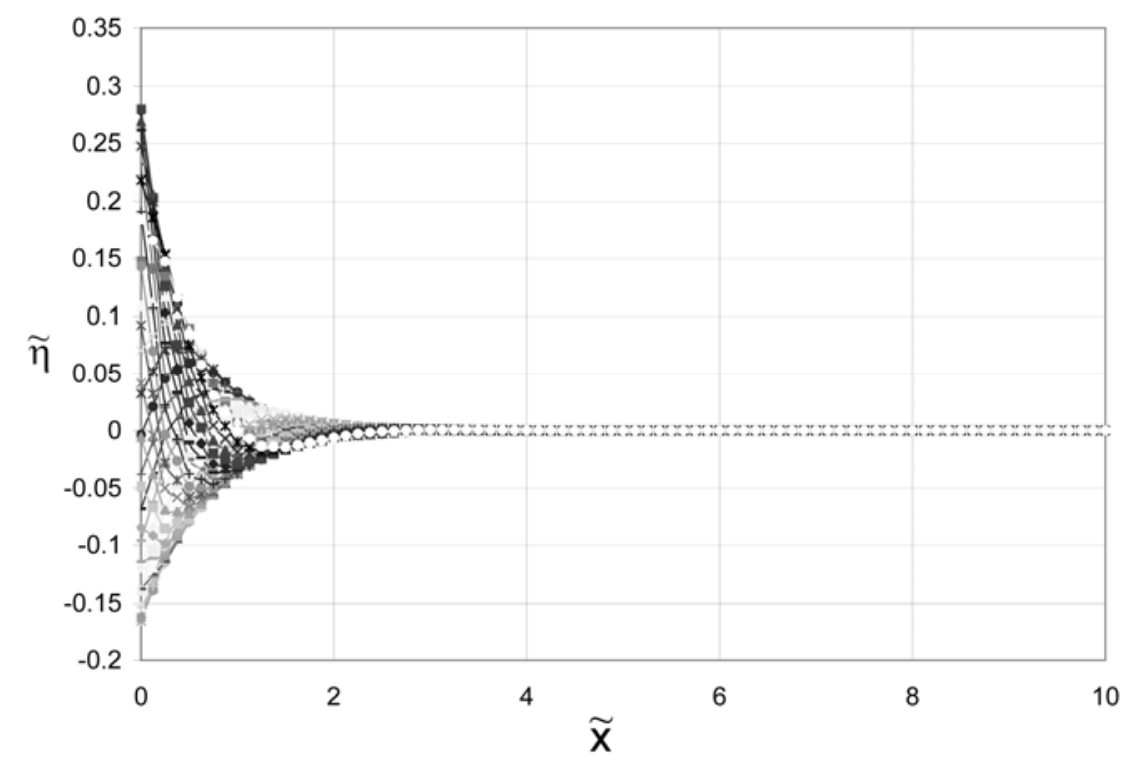

Figure 27. Sample calculation for uniform sediment at mobile-bed equilibrium, showing the variation of dimensionless deviatoric bed elevation $\tilde{\eta}$ (inner variable) with dimensionless distance $\tilde{\mathrm{x}}$ (inner variable) over the complete cycle of the last hydrograph of the run. Note that bed elevation fluctuations are restricted to a hydrograph boundary layer within which $\tilde{\mathrm{x}}$ is less than about 2 .

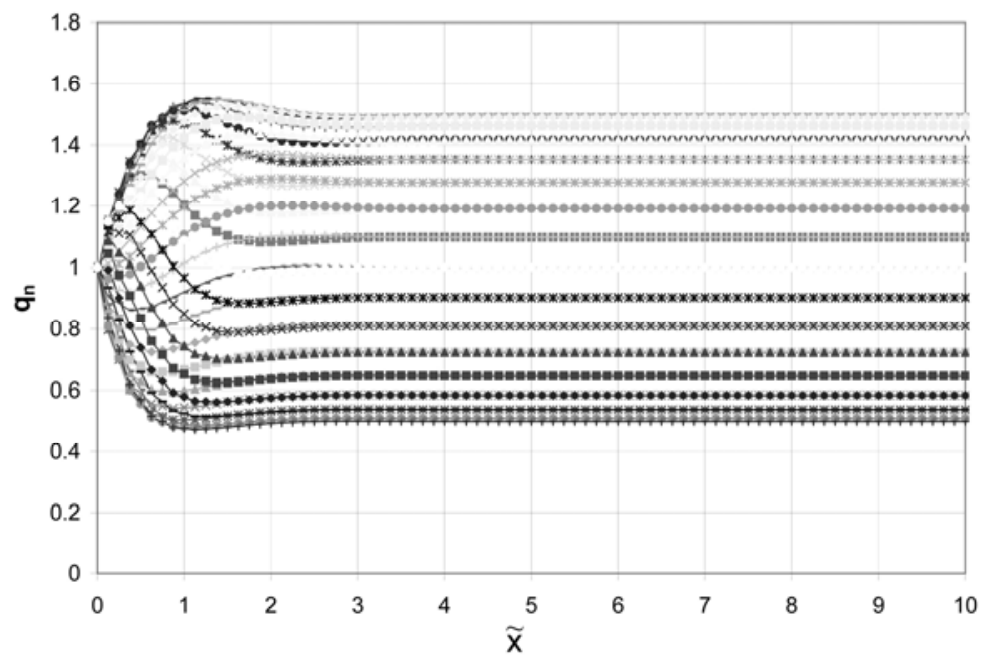

Figure 28. Sample calculation for uniform sediment at mobile-bed equilibrium, showing the variation of dimensionless bedload transport rate $q_{n}$ with dimensionless distance $\tilde{x}$ (inner variable) over the complete cycle of the last hydrograph of the run. Note that $\mathrm{q}_{\mathrm{n}}$ is held constant at the feed point $(\tilde{x}=0)$, but varies cyclically with the hydrograph farther downstream. This cyclic variation in time becomes invariant in $\tilde{\mathrm{x}}$ for $\tilde{\mathrm{x}}$ greater than about 2. 


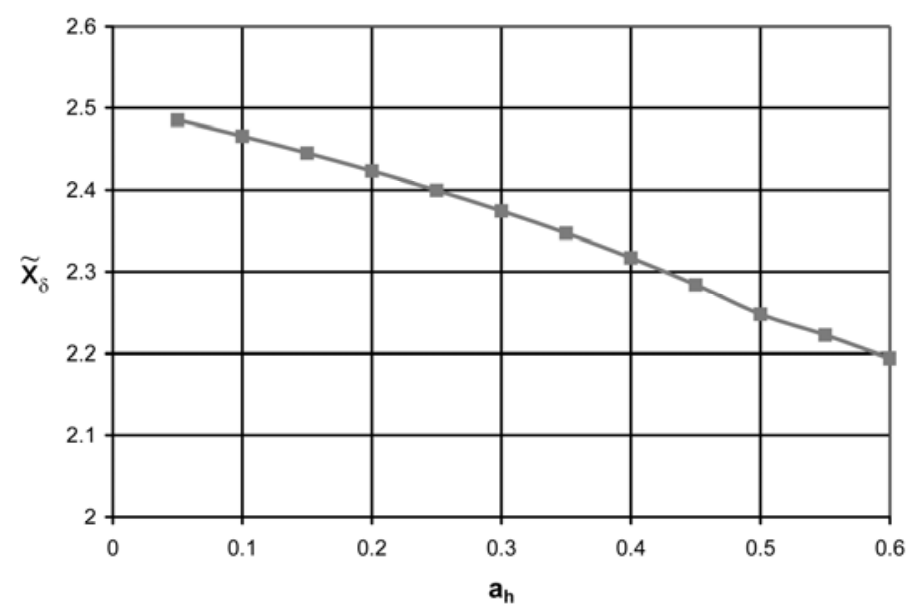

Figure 29. Plot of dimensionless hydrograph boundary layer thickness $\tilde{\mathrm{x}}_{\delta}$ as a function of dimensionless hydrograph amplitude for the case of uniform sediment. A very small tolerance $\chi_{\text {tol }}$ of 0.01 was used for these calculations.

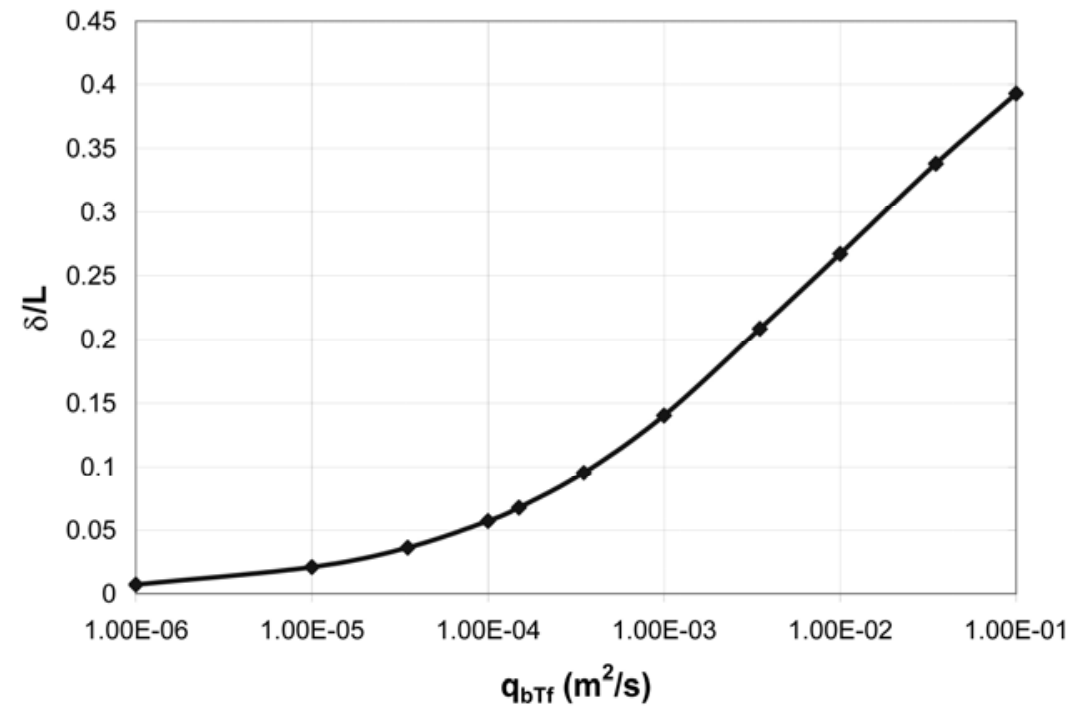

Figure 30. Crude estimate of the variation of the ratio $\delta / L$ of hydrograph boundary layer thickness to reach length versus volume sediment feed rate per unit width $\mathrm{q}_{\mathrm{bTf}}$ for the hydrograph runs of Table 1, based on the analysis for uniform sediment. 